\title{
Mechanical and tribological properties of nanocomposites incorporated with two-dimensional materials
}

\author{
Zhengjia JI ${ }^{1,2}$, Lin ZHANG ${ }^{1}$, Guoxin XIE ${ }^{1, *}$, Wenhu XU ${ }^{3}$, Dan Guo ${ }^{1}, J_{i a n b i n ~ L U O}{ }^{1, *}$, Braham PRAKASH ${ }^{1}$ \\ ${ }^{1}$ State Key Laboratory of Tribology, Department of Mechanical Engineering, Tsinghua University, Beijing 100084, China \\ ${ }^{2}$ College of Mechanical Engineering, Qinghai University, Xi'ning 810016, China \\ ${ }^{3}$ Key Laboratory of Tribology, School of Mechatronics Engineering, Nanchang University, Nanchang 330031, China \\ Received: 29 November 2019 / Revised: 20 March 2020 / Accepted: 07 May 2020 \\ (C) The author(s) 2020 .
}

\begin{abstract}
In recent years, attempts to improve the mechanical properties of composites have increased remarkably owing to the inadequate utilization of matrices in demanding technological systems where efficiency, durability, and environmental compatibility are the key requirements. The search for novel materials that can potentially have enhanced mechanical properties continues. Recent studies have demonstrated that two-dimensional (2D) nanomaterials can act as excellent reinforcements because they possess high modulus of elasticity, high strength, and ultralow friction. By incorporating 2D nanomaterials in a composite, 2D nanomaterial-based composites (2DNBCs) have been developed. In view of this, a critical review of recent mechanical and tribological studies based on 2DNBCs has been undertaken. Matrices such as polymers, ceramics, and metals, as well as most of the representative 2D nanomaterial reinforcements such as graphene, boron nitride $(\mathrm{BN})$, molybdenum disulfide $\left(\mathrm{MoS}_{2}\right)$, and transition metal carbides and nitrides (MXenes) have been included in this review. Their preparation strategies, intrinsic mechanical properties, friction and lubrication performances, strengthening mechanisms, influencing factors, and potential applications have been comprehensively discussed. A brief summary and prospects are given in the final part, which would be useful in designing and fabricating advanced 2D nanocomposites in the future.
\end{abstract}

Keywords: two-dimensional (2D) nanomaterials; composites; mechanical property; friction; wear; lubrication

\section{Introduction}

Over the past decade, two-dimensional (2D) nanomaterials, which refer to ultrathin nanofilms having a thickness of only a single or few atoms, have received increasing attention [1-6]. A number of studies showed that 2D nanomaterials have highly improved properties and can be incorporated in composites to meet different application requirements. Accordingly, novel 2D nanomaterials are very important for a sustainable future.

Since Lee et al. [7] reported graphene's outstanding mechanical properties, research on other 2D nanomaterials has also attracted attention worldwide. Studies on various 2D nanomaterials have significantly increased. Therefore, it is not surprising that $2 \mathrm{D}$ nanomaterials have been employed as promising reinforcements for polymers, metals, and ceramics to produce composites with enhanced mechanical properties. More importantly, it has been observed that even a very small amount of $2 \mathrm{D}$ nanomaterial can lead to a significant enhancement in the mechanical properties. As shown in Fig. 1, the numbers of publications on $2 \mathrm{D}$ materials and $2 \mathrm{D}$

* Corresponding authors: Guoxin XIE, E-mail: xgx2014@tsinghua.edu.cn; Jianbin LUO, E-mail: luojb@tsinghua.edu.cn 


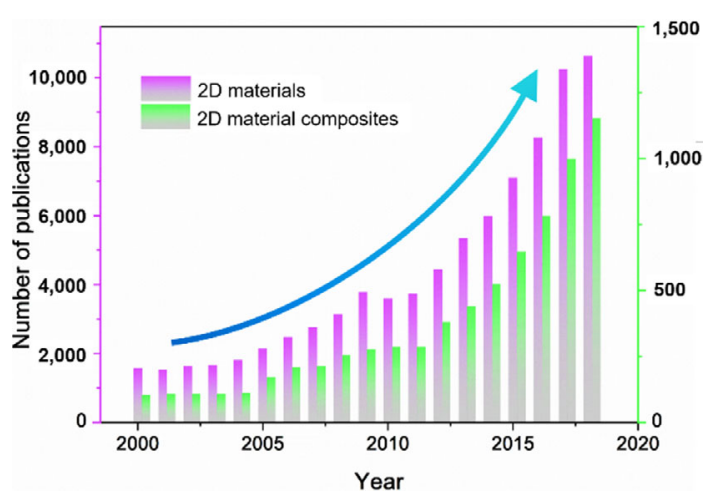

Fig. 1 Statistical data of articles on 2D materials and 2D material composites published during 2000-2018 based on the Web of Science database.

material composites have increased tremendously during the last decade. In view of the excellent mechanical properties and possibility for chemical modification, graphene has been applied in various fields ranging from aerospace to biomedicine. Inspired by the success of graphene-based nanocomposites, considerable effort has been devoted to incorporating other 2D materials in a number of composites as well as the exploration of their potential for various applications. Further, 2DNBCs have already attracted significant attention in many different fields. However, their mechanical and tribological applications have not yet been adequately explored. Recent studies have demonstrated that some novel ultrathin 2D nanomaterials possess excellent mechanical properties. For engineering applications, improving the mechanical properties is one of the most critical and challenging aspects in the technical advancement of these materials.

Many researchers are attempting to understand the reinforcing mechanism of composites with new 2D materials to improve their mechanical and tribological properties and achieve higher efficiency and longer durability for different engineering applications.

According to their chemical elements and atomic arrangements, all 2D nanomaterials can be typically classified into five categories: (1) Xenes, (2) transition metal carbides and nitrides (MXenes), (3) transition metal dichalcogenides (TMDs), (4) nitrides, and (5) organic frameworks. More specifically, (1) Xenes are composed of only one type of element, such as carbon, silicon, and phosphorous. A typical example is graphene, which represents the carbon material of this type. Other examples are silicone, phosphorene [8], and borophene. (2) MXenes, where $M$ is an early transition metal (e.g., Ti, V, and Mo) and $\mathrm{X}$ is carbon or nitrogen, are novel 2D nanomaterials discovered in 2011 [9-11]. (3) TMDs consist of hexagonal layers of metal atoms (M) sandwiched between two layers of chalcogen atoms $(X)$ with a $\mathrm{MX}_{2}$ stoichiometry, such as $\mathrm{MoS}_{2}, \mathrm{MoSe}_{2}$, and $\mathrm{WS}_{2}$. (4) A typical 2D nitride is hexagonal boron nitride (h-BN). (5) 2D organic frameworks include metalorganic frameworks (2DMOFs) and covalent-organic frameworks (2DCOFs) [12]. One of the most characteristic features of $2 \mathrm{D}$ organic frameworks is the presence of micropores or mesopores within the layer. All 2D nanomaterials have high in-plane strength, which is attributed to the in-plane covalent bonding [13]. The mechanical properties of some typical 2D nanomaterials are presented in Table 1. Notably, the modulus of phosphorene has been calculated along the different directions owing to its puckered structure.

Although a number of articles concerning 2DNBCs have been published, most of these papers focused on graphene-based nanocomposites [1, 21-24] and reviews regarding their mechanical properties have rarely been reported. This review intends to highlight the mechanical properties such as hardness, tensile strength, Young's modulus ( $Y$ ), and tribological properties of composites reinforced with $2 \mathrm{D}$ nanomaterials from nanoscale to macroscale systems. As illustrated in Fig. 2, based on the elements of the matrices, the composites can be classified into three categories:

Table 1 Mechanical properties of some typical 2D nanomaterials.

\begin{tabular}{cccc}
\hline $\begin{array}{c}\text { 2D } \\
\text { nanomaterial }\end{array}$ & Thickness & $\begin{array}{c}\text { Tensile } \\
\text { strength }(\mathrm{GPa})\end{array}$ & $\begin{array}{c}\text { Elastic modulus } \\
(\mathrm{GPa})\end{array}$ \\
\hline Graphene & - & 125 & $\sim 1,000[14]$ \\
$\mathrm{MoS}_{2}$ & Monolayer & $23[15]$ & $\sim 270[16]$ \\
h-BN & Monolayer & $35[17]$ & $\sim 865$ \\
Silicene & - & - & $\sim 82[14]$ \\
& & - & $\sim 106(\mathrm{z})[18]$ \\
Phosphorene & Monolayer & - & $\sim 41(\mathrm{a})$ \\
Ti ${ }_{2} \mathrm{C}$ & Monolayer & - & $\sim 597[19]$ \\
$\mathrm{MOF}$ & - & - & $\sim 5[20]$ \\
\hline
\end{tabular}




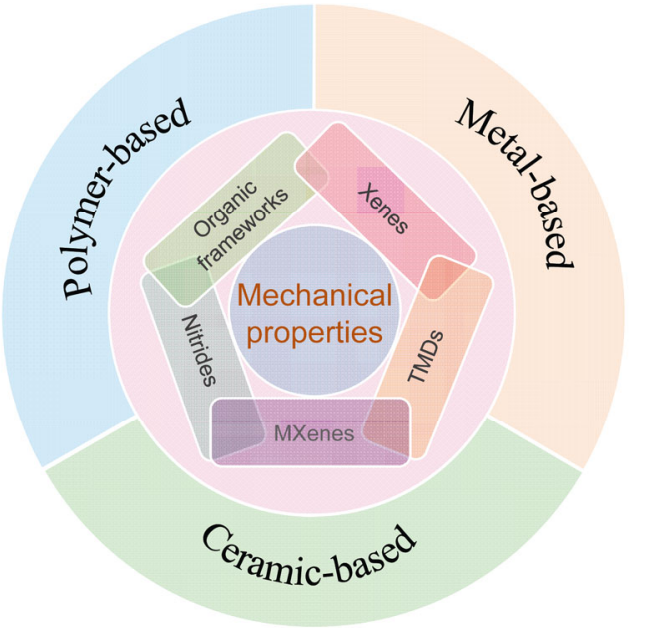

Fig. 2 Types of 2D nanomaterials and composites considered in this review.

polymer, ceramic, and metal composites. This review systematically describes the preparation and mechanical behaviors of various composites based on different matrices and 2D nanomaterials. More importantly, these 2DNBCs are promising for a variety of applications, such as aerospace, energy, and biomedicine, and they have potential to be utilized as structural materials and functional materials because of their excellent mechanical properties. Figure 3 depicts the basic framework of this review. In the following subsections, the preparation of 2DNBCs and the characterization methods of their mechanical properties are introduced.

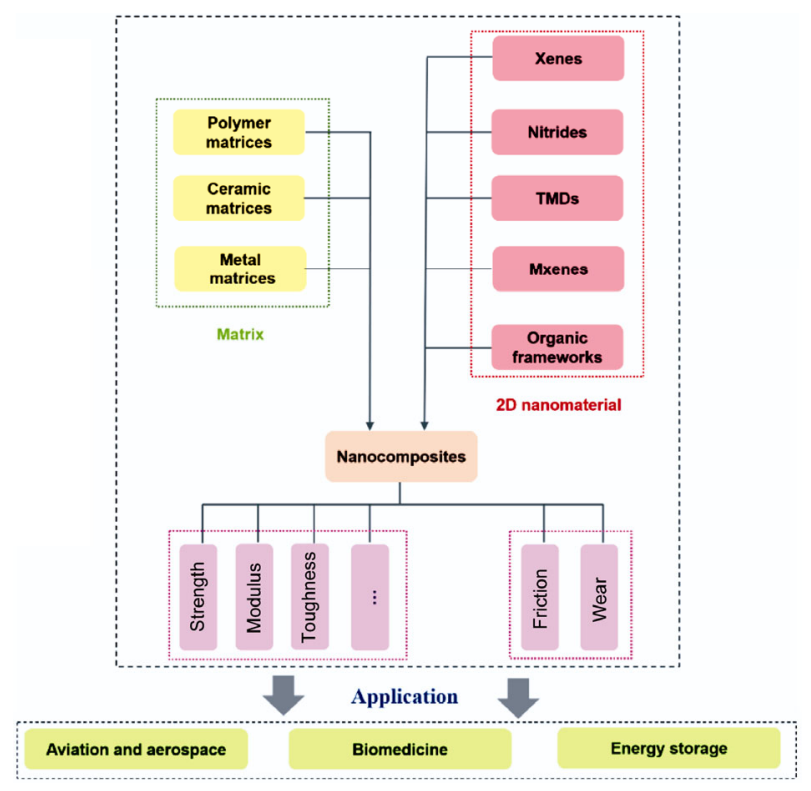

Fig. 3 Basic framework of this review.

\section{Preparation methods}

To achieve excellent mechanical properties, numerous methods, such as cold pressing, hot pressing, microwave sintering, powder metallurgy, and spark plasma sintering, have been developed for the preparation of 2DNBCs. Generally, all these methods can be classified into three categories:

1) For polymer composites, in situ polymerization, solution mixing, and melt blending $[25,26]$ are the most typical fabrication methods. In situ polymerization is a common approach for obtaining uniform dispersion of $2 \mathrm{D}$ nanomaterials in a polymer matrix. The 2D nanomaterials and the monomers or pre-polymers are swollen within the solvent and polymerization is then initiated by adjusting the conditions. Solution mixing is another method of incorporating 2D nanomaterials into a polymer matrix. The 2D nanomaterial and polymer can be dispersed easily in a solvent by ultrasonication or mechanical mixing and the solvent is then removed to obtain the composite. In this technique, the choice of a suitable solvent is a critical issue. There are many successful examples, such as epoxy (EP), polymethyl methacrylate (PMMA), polystyrene, and polytetrafluorothylene (PTFE). Melt blending is performed by high temperature melting without a solvent. This method is generally used for fabricating thermoplastic composites. Recently, the resin transfer molding method has been presented to improve the dispersion of graphene in composites [27]. In this process, EP is incorporated into a three-dimensional (3D) graphene skeleton to prepare composites. Currently, research activities on 2DNBCs are mostly on composites reinforced with graphene or its derivatives. The preparation of other composites has also been achieved through similar strategies.

2) For ceramic composites, many methods have been used and developed, such as powder metallurgy [28, 29], reaction bonding [30], chemical vapor deposition/infiltration [31], sol-gel [32], and polymer infiltration pyrolysis [33]. In the powder metallurgy technique, 2D nanomaterials and matrix powder particles are mixed using ball milling to form composites. Commonly, hot isostatic pressing, vacuum hot pressure sintering, and spark plasma sintering are employed in the later stage. Compared with 
other methods, the powder metallurgy method is cost- and time-effective and is the most promising. Reaction bonding and chemical vapor deposition/ infiltration belong to gas phase processes. With these techniques, good dispersion of 2D nanomaterials in the matrix can be achieved. The sol-gel method can provide uniform dispersion of 2D nanomaterials, which are dispersed early in a molecular precursor solution. The composite can then be formed through the sol-gel reaction. Polymer infiltration pyrolysis is an important method by which ceramic composites can be fabricated from preceramic polymers. The 2D nanomaterials can be dispersed in a liquid phase preceramic polymer beforehand.

3) For metal composites, the fabrication methods are mostly similar to those described above. For instance, both powder metallurgy [34] and melt blending are the most popular methods. However, there are some special methods for fabricating metal matrix composites. Electrochemical deposition and thermal spray are often reported in Ref. [35]. The electrochemical deposition method is an attractive approach for fabricating composite films. As reported, metal injection molding is one of the special ways [35]. Recently, additive manufacturing and molecular-level mixing techniques have also been developed [36, 37]. In a previous review by Naseer et al. [38], these preparation methods have been discussed in detail.

Based on the summary (Table 2), the dispersion of $2 \mathrm{D}$ nanomaterials in a matrix is a crucial step and a key challenge in the production of composites. In recent years, a variety of processing routes for dispersing 2D nanomaterial fillers into matrices, such as liquid phase blending, melt mixing, and freezing-dried masterbatch strategy, have been reported [30, 35-37].

\section{Characterization methods}

Mechanical properties are important factors in the structural and functional applications of composites. Many studies have focused on the qualitative and quantitative characterization of the mechanical properties of various composites [47]. The characterization methods frequently used in studying the mechanical properties of 2DNBCs are briefly described as follows.

\subsection{Universal testing machine approach}

The universal testing machine is a conventional

Table 2 Summary of preparation methods for 2DNBCs.

\begin{tabular}{|c|c|c|c|c|}
\hline Materials & Method & Advantages & Disadvantages & Ref. \\
\hline \multirow{3}{*}{$\begin{array}{l}\text { Polymer } \\
\text { matrix }\end{array}$} & In situ polymerization & $\begin{array}{l}\text { Excellent adhesion and } \\
\text { dispersion }\end{array}$ & $\begin{array}{l}\text { Complicated to operate, high } \\
\text { cost, and only used in lab }\end{array}$ & [39] \\
\hline & Solution mixing & Flexibility in various materials & Hard to remove solution & {$[40-42]$} \\
\hline & Melt blending & Simple process, eco-friendly & $\begin{array}{l}\text { Unsuitable for thermosetting } \\
\text { resin }\end{array}$ & {$[43]$} \\
\hline \multirow{5}{*}{$\begin{array}{l}\text { Ceramic } \\
\text { matrix }\end{array}$} & Powder metallurgy & Easy operation, saving in time & $\begin{array}{l}\text { Environmental pollution, } \\
\text { destructive to 2D materials }\end{array}$ & {$[28,29]$} \\
\hline & Reaction bonding & $\begin{array}{l}\text { Lower processing time, high } \\
\text { densification }\end{array}$ & High energy consumption & {$[30]$} \\
\hline & $\begin{array}{l}\text { Chemical vapor } \\
\text { deposition/infiltration }\end{array}$ & Less energy required & Difficult control in shape & {$[31]$} \\
\hline & Sol-gel & Excellent dispersion & Only used in lab & {$[32]$} \\
\hline & $\begin{array}{l}\text { Polymer infiltration } \\
\text { pyrolysis }\end{array}$ & Steady quality & Less raw material sources & {$[33]$} \\
\hline \multirow{3}{*}{$\begin{array}{l}\text { Metal } \\
\text { matrix }\end{array}$} & Powder metallurgy & Easy operation, low cost & Environmental pollution & {$[44,45]$} \\
\hline & Melting blending & $\begin{array}{l}\text { Excellent dispersion of } 2 \mathrm{D} \\
\text { materials }\end{array}$ & $\begin{array}{l}\text { High cost, dangerous, } \\
\text { destructive to 2D materials }\end{array}$ & {$[46]$} \\
\hline & Additive manufacturing & $\begin{array}{l}\text { Ability to form various shapes, } \\
\text { easy to industrialize, and } \\
\text { environment-friendliness }\end{array}$ & Poor densification & {$[36]$} \\
\hline
\end{tabular}


equipment for measuring the tensile, compressive, and shear strengths. It is worth pointing out that most of the composites can be tested by this approach according to the relevant standard. Different standards have been developed by different countries and organizations. Several studies have applied this approach to characterize composites including graphene/EP [47], h-BN/poly [2,2'-(p-oxydiphenylene)-5,5'-bibenzimidazole] (OPBI) [48], and graphene/Cu [49].

\subsection{Dynamic mechanical analysis (DMA)}

DMA is another typical strategy that has been extensively used to study the elastic modulus and loss factor of composites [50,51]. It is most widely used for determining typical stress-strain curves and interfacial adhesion of polymeric composite systems. For example, the storage modulus and loss angle tangent of $\mathrm{MoS}_{2} /$ chitosan as a function of temperature were shown in Ref. [52]. The forced frequency and free resonance are two typical approaches for calculating the modulus and viscosity values. It has been found that the DMA method is more suitable for polymer composites [50].

\subsection{Finite element approach}

Calculation methods are also effective for evaluating the mechanical properties of composites. The modulus of 2DNBCs can be calculated by the Mori Tanaka equation [53] and the Halpin-Tsai equation [54] or the modified Halpin-Tsai equation [55, 56]. The modified Halpin-Tsai equation is as follows:

$$
\begin{gathered}
E_{\mathrm{C}}=\left\{\frac{3}{8}\left[\frac{1+\left(2 L_{\mathrm{G}} / 3 T_{\mathrm{G}}\right) \eta_{\mathrm{L}} V_{\mathrm{G}}}{1-\eta_{\mathrm{L}} V_{\mathrm{G}}}\right]+\frac{5}{8}\left[\frac{1+2 \eta_{\mathrm{T}} V_{\mathrm{G}}}{1-\eta_{\mathrm{T}} V_{\mathrm{G}}}\right]\right\} E_{P} \\
\eta_{\mathrm{L}}=\frac{\left(E_{\mathrm{G}} / E_{\mathrm{P}}\right)-1}{E_{\mathrm{G}} / E_{\mathrm{P}}+2 L_{\mathrm{G}} / 3 T_{\mathrm{G}}} \\
\eta_{\mathrm{T}}=\frac{\left(E_{\mathrm{G}} / E_{\mathrm{P}}\right)-1}{E_{\mathrm{G}} / E_{\mathrm{P}}+2}
\end{gathered}
$$

where $E_{\mathrm{C}}$ is the $Y$ of the composite with randomly oriented graphene, $E_{\mathrm{G}}$ is the tensile modulus of graphene, $E_{\mathrm{P}}$ is the tensile modulus of polymer, $L_{\mathrm{G}}$ and $T_{G}$ represent the length and thickness of graphene, respectively, and $V_{\mathrm{G}}$ is the volume fraction of graphene in the matrix. $\eta_{\mathrm{L}}$ and $\eta_{\mathrm{T}}$ are dimensionless parameters.

$$
E_{\text {paral }}=\left[\frac{1+\left(2 L_{\mathrm{G}} / 3 T_{\mathrm{G}}\right) \eta_{\mathrm{L}} V_{\mathrm{G}}}{1-\eta_{\mathrm{L}} V_{\mathrm{G}}}\right] E_{\mathrm{P}}
$$

where $E_{\text {paral }}$ is the $Y$ of the composites with unidirectionally distributed graphene. Apparently, the calculation method is an effective way of deriving the theoretical value of $Y$.

Based on these relevant equations, simulation methods, such as finite element models [57, 58], molecular dynamics [59-62], and 3D computational models [63], are developed into effective routes for predicting the mechanical properties of 2DNBCs, as displayed in Fig. 4.

\subsection{Nanoindentation method}

The nanoindentation method has been used since the 1970s and has become one of the most effective methods for determining the mechanical properties of composites since the early 2000s. Nanoindentation is a microscopic method that allows characterization through small-volume deformations. Atomic force microscopy (AFM) nanoindentation is one of the most effective ways for investigating nanomechanical properties such as normal hardness and elastic modulus [64, 65]. Based on force curves and the approach by $\mathrm{Du}$ et al. [66], the elastic modulus $(E)$ of composites can be extracted from the following equation:

$$
\frac{1}{E_{\mathrm{r}}}=\frac{\left(1-v^{2}\right)}{E}+\frac{\left(1-v_{i}^{2}\right)}{E_{\mathrm{i}}}
$$

(a)

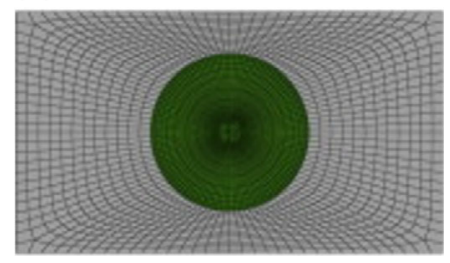

(b)

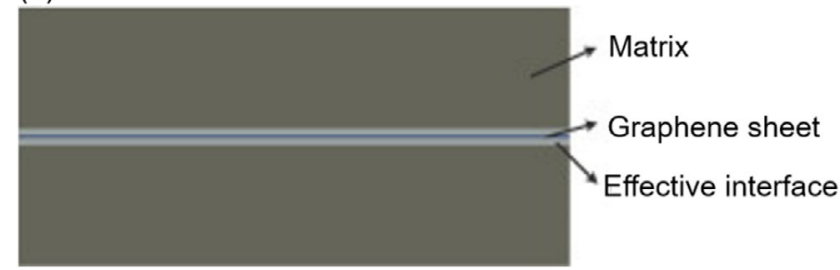

Fig. 4 (a, b) 3D computational model of the effective interface properties between a graphene sheet and polymer matrix. Reproduced with permission from Ref. [63], (C) Elsevier B.V. 2014. 
where $E_{\mathrm{r}}$ and $E_{\mathrm{i}}$ are the reduced modulus and elastic modulus of the indenter, respectively, while $v$ and $v_{i}$ are the Poisson's ratios of the composite and indenter, respectively.

\subsection{Tribological testing}

As one important aspect of the mechanical properties of composites, the tribological properties have drawn much attention and need to be considered. To measure the coefficient of friction (COF) and wear rate, there are many different tribometers employing different test configurations such as pin (or ball) on disc, roller on plate, and block on ring $[67,68]$. The COF is calculated from the frictional force and normal load. The wear rate is generally in the form of specific wear rate, which is calculated by the following equation:

$$
W_{S}=\frac{\Delta m}{\rho L F_{\mathrm{N}}}
$$

where $\Delta m$ and $\rho$ are the mass loss and density of the composite, respectively, $L$ is the sliding distance, and $F_{\mathrm{N}}$ is the normal load.

Since 2DNBCs consist of various matrices and 2D nanomaterials, their mechanical properties can be significantly altered by adjusting the chemical composition, microstructure, and content of 2D nanomaterials. The addition of very low amounts of 2D nanomaterials significantly improves the mechanical properties of a matrix. Thus, the mechanical properties and behaviors of 2DNBCs are complex and challenging.

\section{Mechanical and tribological properties}

First, the main concepts should be introduced. In general, the interatomic bonds of composites mainly determine their mechanical properties [69]. $Y$, which is one of the most important mechanical properties, depends on the spring constant of the bond $(k)$ and the interatomic distance $\left(r_{0}\right)$. It can be expressed by the following formula: $Y=k / r_{0}$ [69]. It should be noted that the spring constant is a crucial term. For example, the value of the carboncarbon bond is from 500 to $1,000 \mathrm{~N} / \mathrm{m}$ and that of the metal or ionic bond is relatively lower [70]. If $k$ of the material changes, the properties also change. Hence, the composite $Y$ is greatly influenced by the matrix type and filler type as well as the interface bonding type between the matrix and filler (i.e., hydrogen bond).

In recent years, 2D nanomaterials such as graphene, $\mathrm{BN}$, and $\mathrm{MoS}_{2}$ [52] have been incorporated into a wide range of matrices for improving the mechanical performance. In the following sections, recent developments in the mechanical properties of 2DNBCs, from polymer composites to metal composites, are discussed. For comparison, the salient mechanical properties based on previous studies are summarized in Table 3.

Table 3 Summary of mechanical properties of 2DNBCs.

\begin{tabular}{|c|c|c|c|c|c|c|c|}
\hline $\begin{array}{l}\text { 2D materials/the } \\
\text { optimum content }\end{array}$ & Matrix & $\begin{array}{c}\text { Tensile } \\
\text { strength } \\
(\mathrm{MPa}) / \text { increase }\end{array}$ & $\begin{array}{c}\text { Tensile } \\
\text { modulus } \\
(\mathrm{GPa}) / \text { increase }\end{array}$ & $\begin{array}{c}\text { Elongation } \\
\text { at break }(\%)\end{array}$ & $\begin{array}{l}Y(\mathrm{GPa}) / \\
\text { increase }\end{array}$ & $\begin{array}{c}\text { Bending } \\
\text { strength } \\
(\mathrm{MPa}) / \text { increase }\end{array}$ & Ref. \\
\hline $\begin{array}{l}\text { Functionalized graphene } \\
\text { (FGS) }(0.75 \mathrm{wt} \%)\end{array}$ & Polyimide (PI) & $204.9 / 59 \%$ & $2.93 / 62 \%$ & 14.2 & - & - & {$[71]$} \\
\hline Graphene $(2 \mathrm{wt} \%)$ & $\begin{array}{l}\text { Polyvinyl chloride } \\
\text { (PVC) }\end{array}$ & $55 / 130 \%$ & 一 & 40 & $2 / 58 \%$ & 一 & {$[72]$} \\
\hline $\mathrm{MoS}_{2}(4 \mathrm{wt} \%)$ & $\begin{array}{c}\text { Waterborne } \\
\text { polyurethane (WPU) }\end{array}$ & $28 / 140 \%$ & - & - & $0.205 / 85 \%$ & - & {$[73]$} \\
\hline Graphene (1 wt\%) & $\begin{array}{l}\text { Polyetheretherketo } \\
\text { ne-carbon fiber } \\
\text { (PEEK-CF) }\end{array}$ & $160 / 60 \%$ & - & - & $7 / 52 \%$ & - & {$[43]$} \\
\hline Graphene (3 vol\%) & PTFE & $21.5 / 10 \%$ & - & - & $2.62 / 223 \%$ & - & {$[74]$} \\
\hline $\mathrm{BN}(1.0 \mathrm{wt} \%)$ & $\mathrm{Al}_{2} \mathrm{O}_{3}$ & & - & - & - & $432.8 / 58.6 \%$ & {$[75]$} \\
\hline $\mathrm{MoS}_{2}(7 \mathrm{wt} \%)$ & $\begin{array}{l}\text { Polyvinylidene } \\
\text { fluoride (PVDF) }\end{array}$ & $42 / 61.5 \%$ & - & 470 & - & - & {$[76]$} \\
\hline Graphene $(0.5 \%)$ & $\mathrm{Cu}$ & $164 / 49.1 \%$ & - & - & - & - & {$[77]$} \\
\hline
\end{tabular}


(Continued)

\begin{tabular}{|c|c|c|c|c|c|c|c|}
\hline $\begin{array}{l}\text { 2D materials/the } \\
\text { optimum content }\end{array}$ & Matrix & $\begin{array}{l}\text { Tensile strength } \\
(\mathrm{MPa}) / \text { increase }\end{array}$ & $\begin{array}{c}\text { Tensile } \\
\text { modulus } \\
(\mathrm{GPa}) / \text { increase }\end{array}$ & $\begin{array}{c}\text { Elongation } \\
\text { at break }(\%)\end{array}$ & $\begin{array}{l}Y(\mathrm{GPa}) / \\
\text { increase }\end{array}$ & $\begin{array}{c}\text { Bending } \\
\text { strength } \\
\text { (MPa)/increase }\end{array}$ & Ref. \\
\hline Graphene $(0.5 \%)$ & $\mathrm{Ti}$ & $1021 / 20.1 \%$ & $125 / 14.6 \%$ & 9.3 & - & - & {$[44]$} \\
\hline $\mathrm{BN}(2 \%)$ & $\begin{array}{l}\text { Polyvinyl alcohol } \\
\text { (PVA) }\end{array}$ & $95 / 98 \%$ & - & - & - & - & {$[78]$} \\
\hline $\mathrm{BN}(3 \%)$ & PMMA & & - & - & $5.11 / 130 \%$ & - & [79] \\
\hline Graphene $(0.05$ wt\%) & Cementitious & $5 / 79 \%$ & - & - & - & - & {$[80]$} \\
\hline $\mathrm{BN}(0.3 \mathrm{wt} \%)$ & PMMA & $42 / 11 \%$ & - & - & $2.13 / 22 \%$ & - & {$[17]$} \\
\hline Graphene & $\mathrm{Al}$ & $120 / 26 \%$ & - & - & - & - & {$[81]$} \\
\hline $\mathrm{BN}(2.5 \mathrm{wt} \%)$ & Borosilicate glass & & - & - & 74 & 112 & {$[82]$} \\
\hline $\mathrm{BN}(0.2 \mathrm{wt} \%)$ & PVA & $140 / 16 \%$ & - & - & $3.4 / 36 \%$ & - & {$[83]$} \\
\hline $\operatorname{MoS}_{2}(5 \mathrm{wt} \%)$ & PVA & $105 / 24 \%$ & - & 150 & - & - & {$[84]$} \\
\hline $\begin{array}{c}\mathrm{MoS}_{2} \text { with POSS } \\
(2 \mathrm{wt} \%)\end{array}$ & PVA & $58 / 57 \%$ & - & - & - & - & [85] \\
\hline $\mathrm{BN}(0.5 \mathrm{wt} \%)$ & $\begin{array}{l}\text { Cellulose acetate } \\
\text { (CA) }\end{array}$ & 115 & 7 & - & - & - & {$[86]$} \\
\hline $\mathrm{BN}(0.3 \mathrm{wt} \%)$ & PMMA & $42 / 11 \%$ & - & - & $2.3 / 22 \%$ & - & {$[87]$} \\
\hline $\mathrm{BN}$ & PMMA & & - & 34.4 & $0.803 / 9 \%$ & - & {$[88]$} \\
\hline Ni-GNPs (0.5 vol\%) & $\mathrm{Cu}$ & $281 / 24 \%$ & - & 11.9 & - & - & {$[89]$} \\
\hline $\mathrm{BN}(1.5 \mathrm{wt} \%)$ & $\begin{array}{l}\text { Styrene butadiene } \\
\text { rubber (SBR) }\end{array}$ & $48.7 / 150 \%$ & - & 380 & - & - & {$[90]$} \\
\hline $\begin{array}{l}\text { Reduced graphene } \\
\text { oxide }(\mathrm{rGo})(1.5 \mathrm{wt} \%)\end{array}$ & $\mathrm{Ni}$ & 948 & - & 12.1 & - & - & [91] \\
\hline Graphene (1.8 vol\%) & PVA & $42 / 150 \%$ & $1.04 / 940 \%$ & 98 & - & - & {$[55]$} \\
\hline Graphene (1 wt $\%)$ & Al5083 alloy & $470 / 56 \%$ & - & 3 & - & - & {$[92]$} \\
\hline Graphene & $6063 \mathrm{Al}$ & $277 / 23 \%$ & - & 14.7 & - & - & {$[93]$} \\
\hline $\mathrm{BN}(2 \mathrm{wt} \%)$ & $\begin{array}{l}\text { Polyarylene ether } \\
\text { nitrile (PEN) }\end{array}$ & $111 / 10 \%$ & - & 2.75 & - & - & {$[41]$} \\
\hline rGO $(1 \mathrm{wt} \%)$ & AlN & & - & - & $322 /-10 \%$ & - & {$[94]$} \\
\hline GO & $\begin{array}{l}\text { Polyelectrolyte } \\
\text { (PEC) }\end{array}$ & $155 / 370 \%$ & - & 9 & $4.41 / 270 \%$ & - & {$[95]$} \\
\hline Graphene ( $5 \mathrm{wt} \%)$ & $\mathrm{EP}$ & $62 /-52 \%$ & $4 / 48 \%$ & - & & - & {$[96]$} \\
\hline Graphene $(2 \mathrm{wt} \%)$ & $\begin{array}{c}\text { Polybutylene } \\
\text { succinate (PBS) }\end{array}$ & $37.2 / 21 \%$ & & 19 & - & - & {$[97]$} \\
\hline Silane-f-GO $(0.1 \mathrm{wt} \%)$ & EP & $80 / 45 \%$ & $3.3 / 6 \%$ & - & - & - & {$[98]$} \\
\hline Graphene (1.0 vol\%) & Copper & $32039 \%$ & & - & $132 / 61 \%$ & - & [99] \\
\hline PBA-BN $(0.3$ wt \%) & EP & $71.9 / 54 \%$ & $3.34 / 21 \%$ & - & - & - & {$[100]$} \\
\hline $\mathrm{Ti}_{3} \mathrm{C}_{2} \mathrm{~T}_{x}$ & $\mathrm{NH}_{2}-\mathrm{CF} / \mathrm{EP}$ & $1210.9 / 40.8 \%$ & - & - & - & - & [101] \\
\hline Graphene $(0.1 \mathrm{wt} \%)$ & Ag/PVA & $141.1 / 16.4 \%$ & - & - & $0.701 / 126.9 \%$ & - & {$[102]$} \\
\hline Graphene & Polypropylene (PP) & $61.57 / 81 \%$ & - & 19 & $2.314 / 100 \%$ & - & {$[26]$} \\
\hline
\end{tabular}

\subsection{Polymer composites}

To date, polymer composites enhanced with 2D nanomaterials such as graphene, $\mathrm{MoS}_{2}, \mathrm{BN}, \mathrm{MXene}$, and MOF [103] have been widely reported and applied. In this section, the recent developments on both strength and friction of 2DNBCs are described.

\subsubsection{Strength}

Most of the studies on polymer composites have been aimed at exploiting the high mechanical strength of fillers such as fibers [104, 105], nanoparticles 
[106-108], whiskers [109, 110], and nanosheets [111-116]. Compared with other fillers, 2D nanomaterials have attracted more attention because of their unique planar structure and unconventional mechanical properties, as illustrated in Fig. 5. Herein, the critical strength of polymer composites incorporated with 2D nanomaterials is discussed in detail.

As presented in Fig. 6, the layered structure of typical 2D nanomaterials investigated by transmission electron microscopy (TEM) and AFM shows good dispersion in the composites. Four factors are responsible for enhancing the mechanical strength of polymer composites reinforced by 2D materials: (1) the large aspect ratio and high intrinsic mechanical properties of 2D materials [26], (2) the strong interfacial interaction between the $2 \mathrm{D}$ material and polymer matrix [26, 84, 118-120], (3) the homogeneous dispersion of 2D materials [78, 84, 118], and (4) the increased crystallinity [121].

As organic materials, polymers are highly flexible

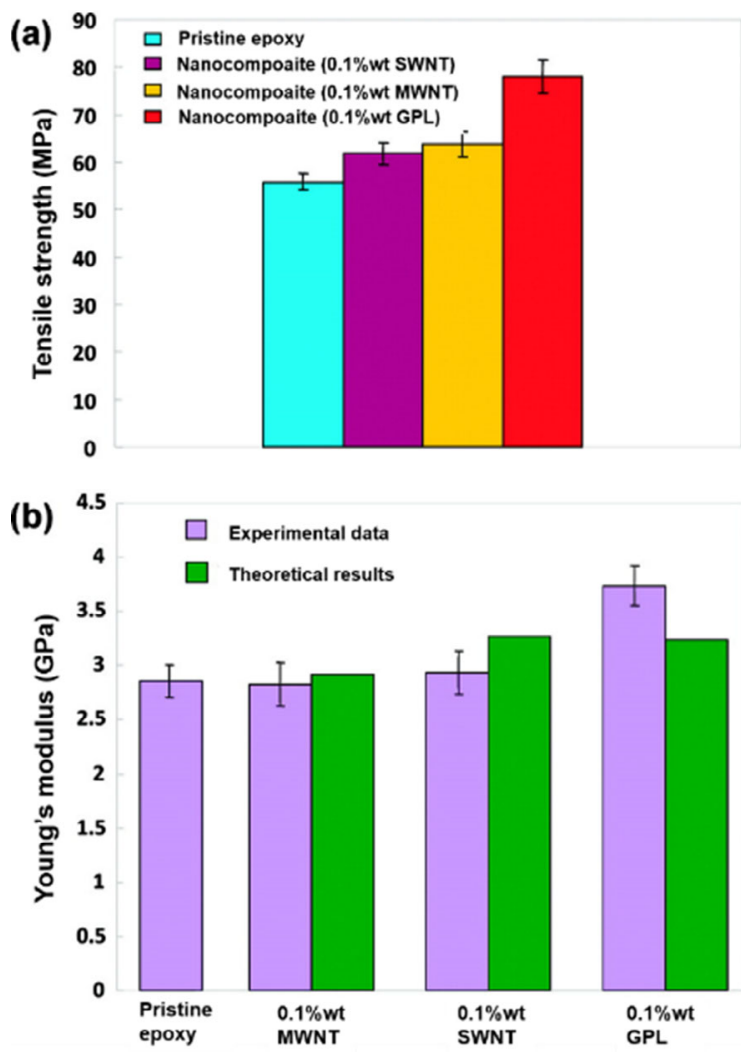

Fig. 5 (a) Tensile strength and (b) $Y$ of pristine EP, singlewalled carbon nanotube (SWNT)/EP, multi-walled carbon nanotube (MWNT)/EP, and graphene (GPL)/EP composites. Reproduced with permission from Ref. [117], (C) American Chemical Society 2009. and have poor mechanical properties [122]. However, the addition of 2D nanomaterials significantly improves their characteristics. As a typical example, PVA was reinforced by various $2 \mathrm{D}$ nanomaterials including graphene [123], $\mathrm{BN}$ [78], $\mathrm{MoS}_{2}$ [84], and $\mathrm{Ti}_{3} \mathrm{C}_{2} \mathrm{~T}_{x}[124,125]$. The crystallinity of the PVA polymer was influenced by the addition of graphene or graphene oxide (GO) nanosheets, indicating that 2D nanomaterials act as nucleating agents in the matrix [26]. However, Wang et al. [97] reported that the crystallinity of polybutylene succinate (PBS) remained the same despite the presence of graphene. The addition of $2.0 \mathrm{wt} \%$ graphene in PBS increased the tensile strength and storage modulus by $21 \%$ and $24 \%$, respectively. This is because, at room

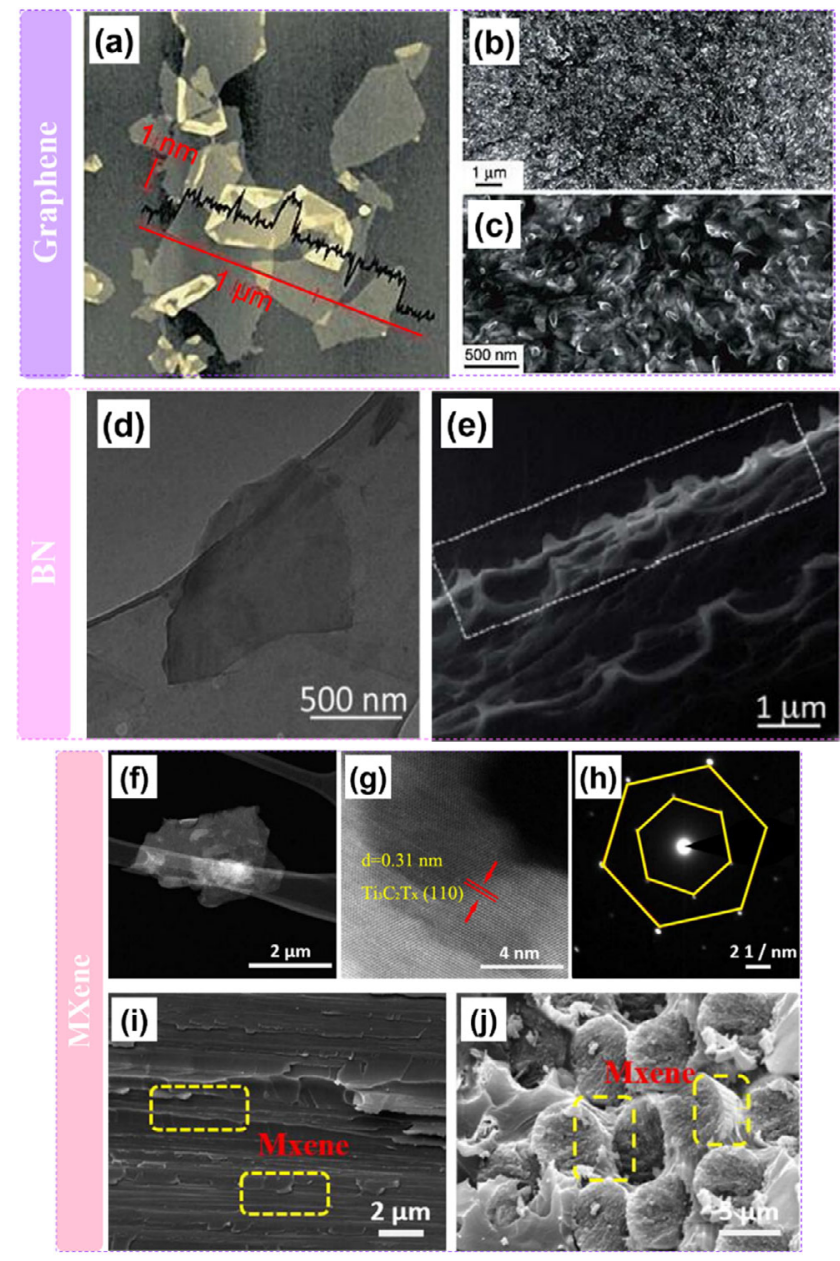

Fig. 6 Morphology images of (a) graphene and (b, c) its composite. Reproduced with permission from Ref. [1], (C) Springer Nature 2006. (d) BN and (e) its composite. Reproduced with permission from Ref. [83], C) RSC 2009. (f-h) MXene and $(i, j)$ its composite. Reproduced with permission from Ref. [101], C Springer Nature 2019. 
temperature, the load transfer across the interface between the graphene and matrix is easily achieved owing to the large aspect ratio and uniform dispersion of graphene in the matrix. Since the crystallinity of PBS remained the same despite the presence of graphene, this could mean that the addition of $2 \mathrm{D}$ nanomaterials does not affect the crystallinity of composites and the improvement in mechanical properties depends mainly on the 2D material rather than on the matrix. The results are consistent with the shear lag theory, which describes the 2D nanomaterial behavior in a matrix [126].

The effect of graphene on the stiffness, strength, and toughness of OPBI was investigated by Wang et al. [51] through an in situ polymerization method. Later, significant progress of composites filled with other 2D nanomaterials has been reported. An appropriate concentration of the well-structured BN enables the enhancement of mechanical properties [48]. The addition of $4 \mathrm{wt} \% \mathrm{BN}$ to OPBI has a similar effect on improving the tensile strength and modulus to that of filling with $0.4 \mathrm{wt} \%$ of graphene [48]. The difference in the amounts may be due to their intrinsic strengths $\left(\sigma_{\text {graphene }} \approx 130\right.$ $\left.\mathrm{GPa}[7,127], \sigma_{\mathrm{BN}} \approx 85 \mathrm{GPa}[128]\right)$.

There are two main strategies for further enhancing the mechanical properties of polymer composites. First, the functionalization, using octa (aminophenyl) silsesquioxane, octadecylamine, fluoride, etc., is an efficient way [129-135], because both dispersion and stress transfer can significantly improve the strength. The functionalization of 2D nanomaterials is conducive to better dispersion [136]. The compatibility of the 2D nanomaterial and the matrix affects the interface energy transfer in composites [76]. Ramanathan et al. [2] added $0.05 \mathrm{wt} \%$ of singlelayer functionalized graphene to PMMA and achieved an increase of $80 \%$ in elastic modulus and $20 \%$ in tensile strength. A similar result was obtained by Qiu et al. [137]. In addition, Xing et al. [138] also claimed that functionalized BN can enhance the mechanical properties of polymers. Another strategy is synergistic effect [102, 139-143]. Owing to the synergistic effect of the $\pi-\pi$ interaction between the one-dimensional (1D) carbon nanotube (CNT) and 2D GO nanosheet as well as the strong interfacial interactions between the PEC matrix and CNT-GO, the production of PEC/GO-CNT composites with higher tensile strength and $Y$ is expected [95]. The incorporation of GO can improve the compressive strength of the PEC complex hydrogel [50]. The GO nanofiller bears most of the applied load in various states owing to its intrinsic high strength. Figure 5 displays a comparison between the tensile strengths and $Y$ of pure EP and different nanocomposites. It is shown that the tensile strengths of the composites are higher than that of the pure matrix. On average, the strength increases by $20 \%$ to $140 \%$. Note that even $0.5 \mathrm{wt} \% \mathrm{MoS}_{2}$ improved the tensile strength of chitosan to $207 \%$ [52]. Finally, it remains a challenge to understand the strengthening mechanisms of 2D nanomaterials in 2DNBCs owing to their diversity and complexity.

\subsubsection{Friction and wear characteristics}

Besides the mechanical strength, 2D nanomaterials can improve the tribological performance of polymers as well, because these $2 \mathrm{D}$ nanomaterials exhibit in-plane mechanical isotropy and a weak interlayer interaction [144]. The good tribological performance, which can be achieved by incorporating 2D nanomaterials in the matrix, comprises two aspects: (1) reduction in COF and (2) enhancement in wear resistance. This section discusses the effect of using 2D nanomaterials as fillers in a polymer matrix on the frictional properties. All the results mentioned for the COF and wear rates are summarized in Table 4. For comparison, various 2D nanomaterials added in the polymer matrix are presented [145-147].

The COF of PTFE is significantly reduced when the added graphene in the matrix is $4.0 \mathrm{wt} \%$ [148]. However, a higher content of graphene may compromise the lubrication property. The addition of graphene to a PTFE matrix decreases the wear rate by three or four orders of magnitude [157]. The friction reduction and improved wear resistance of the composite are attributed to the good dispersion and self-lubrication of 2D nanofillers [144]. Ultrahigh molecular weight polyethylene (UHMWPE) had been reinforced by graphene [158] or $\mathrm{Ti}_{3} \mathrm{C}_{2}$ [156]. The results showed that the $2 \mathrm{D}$ nanomaterial reduced the effective lateral force and increased the wear resistance. Further, 2D nanomaterials can 
Table 4 Tribological properties of polymer composites reinforced with 2D materials.

\begin{tabular}{|c|c|c|c|c|c|c|}
\hline Matrix & 2D material & Method & $\begin{array}{l}\text { Operating } \\
\text { condition }\end{array}$ & $\mathrm{COF}$ & $\begin{array}{c}\text { Wear rate } \\
\left(\mathrm{mm}^{3} /(\mathrm{N} \cdot \mathrm{m})^{-1}\right)\end{array}$ & Ref. \\
\hline PTFE & $\begin{array}{l}4.0 \mathrm{wt} \% \\
\text { graphene }\end{array}$ & $\begin{array}{l}\text { Cold compression and } \\
\text { sintering }\end{array}$ & $20 \mathrm{~N}, 0.1 \mathrm{~m} / \mathrm{s}$ & 0.18 & $7.5 \times 10^{-6}$ & {$[148]$} \\
\hline PTFE & $10 \mathrm{wt} \% \mathrm{MoS}_{2}$ & Cold press and sintering & $5 \mathrm{~N}, 0.12 \mathrm{~m} / \mathrm{s}$ & 0.15 & $2.5 \times 10^{-5}$ & [149] \\
\hline PTFE & $10 \mathrm{wt} \% \mathrm{~g}-\mathrm{C}_{3} \mathrm{~N}_{4}$ & Cold press and sintering & $5 \mathrm{~N}, 0.12 \mathrm{~m} / \mathrm{s}$ & 0.18 & $1.0 \times 10^{-5}$ & {$[149]$} \\
\hline PTFE & $\begin{array}{c}5 \mathrm{wt} \% \\
\text { phosphorene }\end{array}$ & Ball milling and SPS & $3 \mathrm{~N}, 20 \mathrm{~mm} / \mathrm{s}$ & 0.041 & $6.9 \times 10^{-6}$ & {$[150]$} \\
\hline EP & $0.5 \mathrm{wt} \% \mathrm{BN}$ & Mechanical mixing & $5 \mathrm{~N}, 20 \mathrm{~mm} / \mathrm{s}$ & 0.5 & $16 \times 10^{-5}$ & {$[151]$} \\
\hline PI & $2 \mathrm{wt} \% \mathrm{BN}$ & $\begin{array}{l}\text { Mechanical mixing and } \\
\text { spin-coated }\end{array}$ & $3 \mathrm{~N}, 20 \mathrm{~mm} / \mathrm{s}$ & 0.10 & $2.79 \times 10^{-6}$ & {$[152]$} \\
\hline PEEK & 10 vol $\% g-C_{3} \mathrm{~N}_{4}$ & $\begin{array}{l}\text { Mechanical mixing and } \\
\text { hot pressing }\end{array}$ & $50 \mathrm{~N}, 1 \mathrm{~m} / \mathrm{s}$ & 0.6 & $4.0 \times 10^{-7}$ & {$[68]$} \\
\hline $\begin{array}{l}\text { Phenol } \\
\text { formaldehyde }(\mathrm{PF})\end{array}$ & $\begin{array}{c}0.3 \mathrm{wt} \% \\
\text { Graphene oxide }\end{array}$ & Solution mixing & $320 \mathrm{~N}, 2.24 \mathrm{~m} / \mathrm{s}$ & 0.12 & - & {$[153]$} \\
\hline Polyurethane & $3 \mathrm{wt} \% \mathrm{MoS}_{2}$ & Solution mixing & $3 \mathrm{~N}, 60 \mathrm{~mm} / \mathrm{s}$ & 0.10 & $9 \times 10^{-5}$ & {$[145]$} \\
\hline EP & $\begin{array}{c}1.0 \mathrm{wt} \% \\
\mathrm{MoS}_{2} @ \mathrm{PPN}\end{array}$ & Mechanical mixing & $80 \mathrm{~N}, 0.05 \mathrm{~m} / \mathrm{s}$ & 0.58 & $22.3 \times 10^{-5}$ & {$[154]$} \\
\hline $\begin{array}{l}\text { Bismaleimide } \\
\quad(\mathrm{BMI})\end{array}$ & $\begin{array}{c}0.6 \mathrm{wt} \% \\
\mathrm{PHbP} @ \mathrm{rGO} / \mathrm{WS}_{2}\end{array}$ & Solution mixing & $196 \mathrm{~N}, 0.42 \mathrm{~m} / \mathrm{s}$ & 0.13 & $1.22 \times 10^{-6}$ & {$[155]$} \\
\hline UHMWPE & $2.0 \mathrm{wt} \% \mathrm{Ti}_{3} \mathrm{C}_{2}$ & Hot compression mold & $200 \mathrm{~N}, 0.4 \mathrm{~m} / \mathrm{s}$ & 0.128 & - & {$[156]$} \\
\hline EP & $2.0 \mathrm{wt} \% \mathrm{Ti}_{2} \mathrm{CT}_{x}$ & Mechanical mixing & $98 \mathrm{~N}, 0.3 \mathrm{~m} / \mathrm{s}$ & 0.228 & - & [39] \\
\hline
\end{tabular}

significantly contribute to the excellent mechanical properties, lubricity, and thermal conductivity [151]. These 2D nanomaterials also have potential to solve the frictional heat problems of polymer composites. Qiu et al. [154] employed an infrared thermal imager to investigate the melting behavior of composites. The results showed that the addition of $\mathrm{MoS}_{2}$ reduced the frictional heat and retarded the melting wear. In Ref. [159], a 2D nanomaterial was also added in a base oil owing to its good self-lubricating property. Thus, 2D nanomaterials are promising fillers and can significantly enhance the tribological performance of polymer composites because of their good lubricating properties under harsh conditions [160].

To understand the wear mechanism of polymer composites incorporating 2D nanomaterials, many studies have focused on the analysis of the worn surface of composites (Fig. 7). The mechanism reported includes two different categories: (i) slightly abrasive wear [155] and (ii) melting wear [154]. Based on the observation of friction surfaces, many studies have demonstrated that the formation of a loadcarrying transfer layer is the key factor for improving the tribological properties of polymer composites (Fig. 8) [149, 150].

In summary, the friction performance of polymer matrices reinforced with 2D nanomaterials mainly depends on the type and content of the 2D nanomaterial as well as the interfacial bonding. As discussed above, the functionalization of $2 \mathrm{D}$ nanomaterials is an important method for strengthening the interfacial bonding. To further enhance the tribological performance, several challenges related to the interfacial bonding must be tackled urgently [40].

\subsection{Ceramic composites}

Similar to polymer composites reinforced with 2D nanomaterials, ceramic composites require a homogeneous distribution of 2D nanomaterials for improving their mechanical performance. However, designing advanced ceramic composites is still a challenging task owing to interdiffusion and chemical reactions at high temperatures. To address this challenge, novel preparation methods have been developed as described in Section 2. Thus, their mechanical and tribological properties would be 


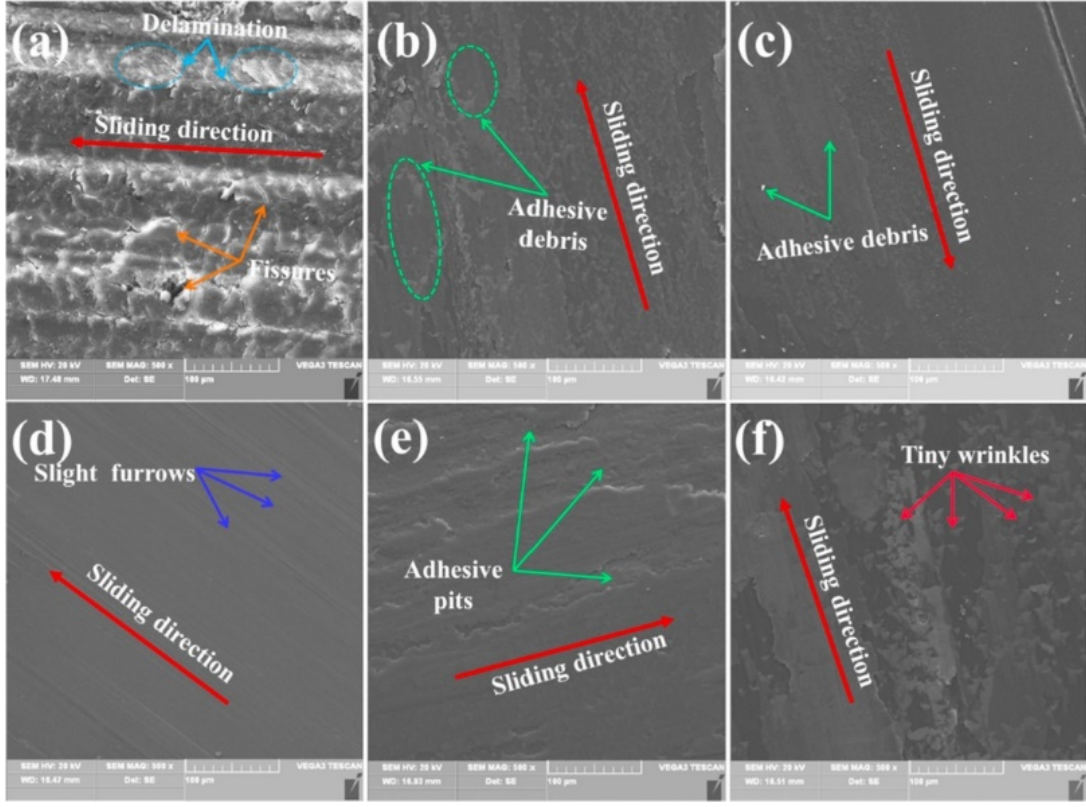

Fig. 7 Scanning electron microscopy images of worn surfaces of (a) bismaleimide resin and its composites incorporating: (b) 0.2 wt $\%$, (c) $0.4 \mathrm{wt} \%$, (d) $0.6 \mathrm{wt} \%$, (e) $0.8 \mathrm{wt} \%$, and (f) $1.0 \mathrm{wt} \%$ PHbP@rGO/WS . Reproduced with permission from Ref. [155], (c) Elsevier Ltd. 2019.
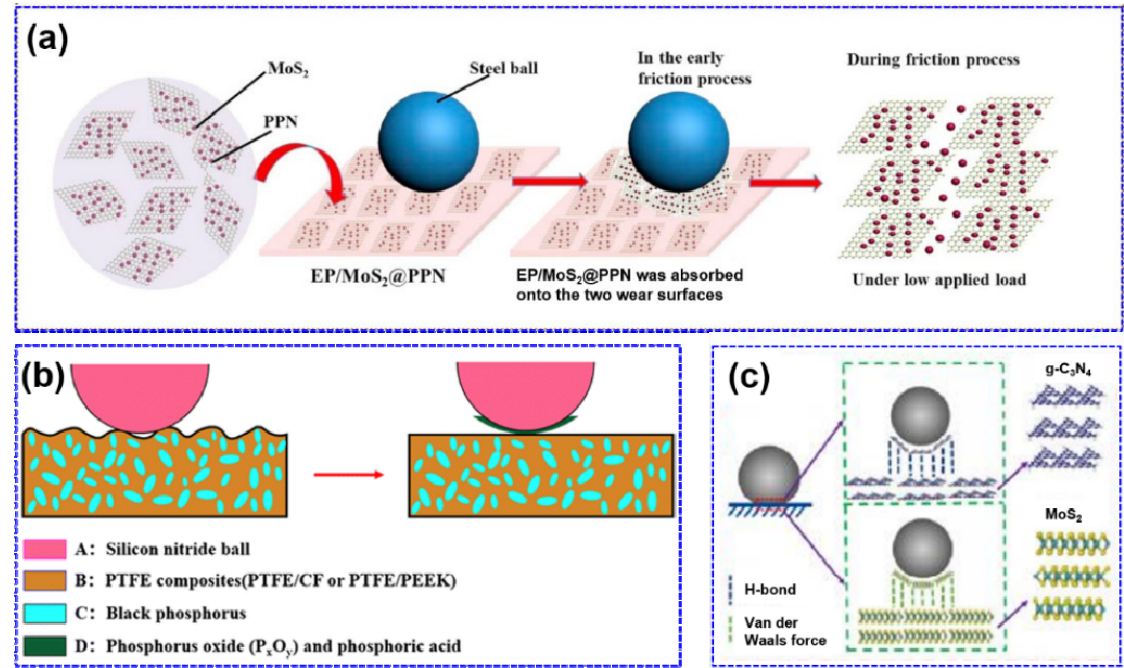

Fig. 8 Schematic of friction mechanism for (a) EP/MoS ${ }_{2} @$ PPN composites. Reproduced with permission from Ref. [154], (C) Elsevier Ltd. 2018. (b) PTFE/phosphorene. Reproduced with permission from Ref. [150], (C) Springer Nature 2018. (c) PTFE/MoS 2 and PTFE/g- $\mathrm{C}_{3} \mathrm{~N}_{4}$. Reproduced with permission from Ref. [149], (C) Springer Nature 2019.

discussed in the following sections.

\subsubsection{Strength}

Graphene-reinforced ceramic composites, which possess the strongest 2D nanomaterial, have been studied extensively [161-170]. Two reviews have already examined critically the effect of graphene $[171,172]$. Even a very small content of graphene can significantly improve the tensile strength and fracture toughness of ceramic composites. For example, the fracture toughness of zirconia ceramics can improve with $0.01 \mathrm{wt} \%$ graphene [161]. Krystek et al. [80] reported that the addition of $0.05 \mathrm{wt} \%$ graphene to ordinary cement results in a significant increase of up to $79 \%$ in the tensile strength. In another example, with increasing graphene content, the flexural strength and fracture toughness of AlN composites initially increased and then decreased 
[166]. Graphene nanosheet (GNS) bridging the crack propagation path indicated the crack bridging effect of GNSs during crack propagation, which in turn, increased the fracture toughness. Furthermore, the microstructure of composites was investigated to explain the reinforcing mechanism of 2D nanomaterials [166]. It was found that the addition of graphene promotes the hydration reaction of both alite and belite, and thus leading to the formation of a large fraction of $3 \mathrm{CaO} \cdot 2 \mathrm{SiO}_{2} \cdot 3 \mathrm{H}_{2} \mathrm{O}(\mathrm{C}-\mathrm{S}-\mathrm{H})$ phase. In fact, the $2 \mathrm{D}$ nanomaterials proved to be superior to the 1D and 3D nanomaterials, such as nanotubes and nanoparticles, in improving the mechanical properties of ceramic matrices [173]. A detailed review by Papageorgiou et al. [24] summarizes the research on improving the mechanical properties of graphene nanocomposites.

Owing to the poor toughness of ceramic matrices, $\mathrm{BN}$ can be used to improve their mechanical properties [174]. Lee et al. [28] explored the mechanical properties of a $\mathrm{BN} / \mathrm{Si}_{3} \mathrm{~N}_{4}$ nanocomposite by the single-edge notched beam method and microstructural analyses. The strengthening mechanism is summarized in Fig. 9. Moreover, it was shown that the introduction of $\mathrm{BN}$ results in the strengthening and toughening of ceramic composites [28, 82, 175].

$\mathrm{MoS}_{2}$ nanoplatelets were also incorporated into bioceramic scaffolds fabricated by selective laser sintering (Fig. 10) by Shuai et al. [15]. At $0.5 \mathrm{wt} \%$ $\mathrm{MoS}_{2}$ nanoplatelets, the compressive strength and fracture toughness of the bioceramic scaffolds improved by $46 \%$ and $24 \%$, respectively. The $\mathrm{MoS}_{2}$ crack bridge/deflection enhances energy dissipation, leading to the improvement.

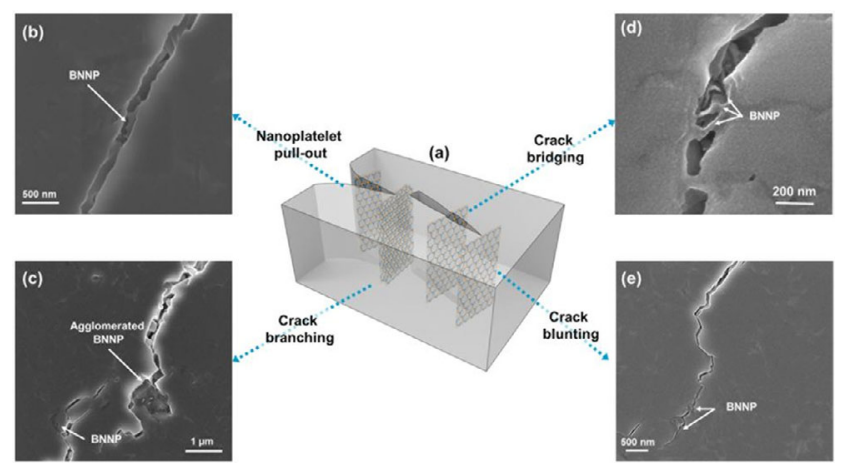

Fig. 9 Microstructure of a ceramic composite reinforced with BN. Reproduced with permission from Ref. [28], (C) Springer Nature 2016.

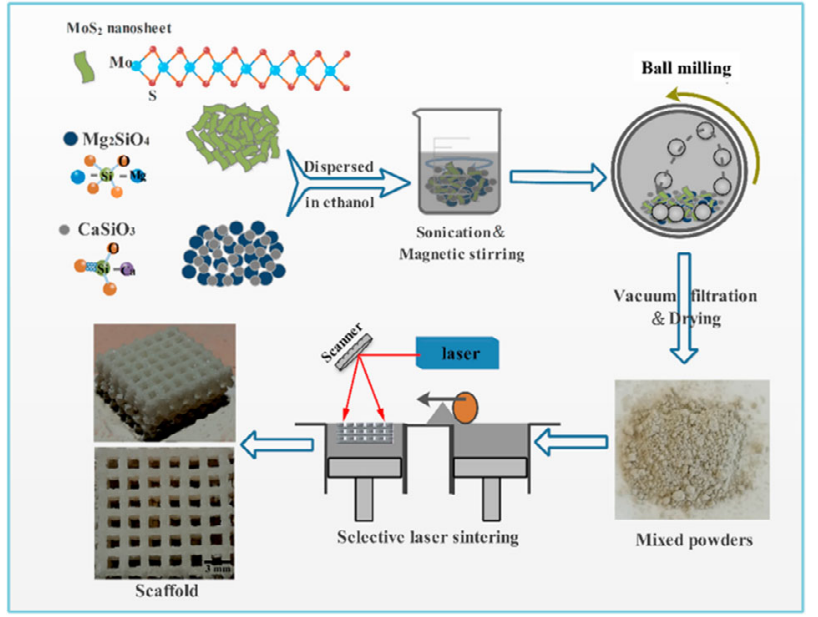

Fig. 10 Fabrication process of a bioceramic scaffold incorporating $\mathrm{MoS}_{2}$. Reproduced with permission from Ref. [15], C Elsevier Ltd. 2017.

MXenes for high-strength composites have attracted much attention and were incorporated into ceramic composites. Incorporating $2 \mathrm{wt} \% \mathrm{Ti}_{3} \mathrm{C}_{2} \mathrm{~T}_{x}$ into an alumina ceramic composite can improve the fracture toughness, bending strength, and hardness to $~ 300 \%$, $\sim 150 \%$, and $\sim 300 \%$, respectively [176]. The hardness and elastic modulus of $\mathrm{ZnO}$ ceramic were increased dramatically with $0.5 \mathrm{wt} \% \quad \mathrm{Ti}_{3} \mathrm{C}_{2} \mathrm{~T}_{x}$ [177]. The microstructure of the nanocomposites and the outstanding intrinsic mechanical properties of $\mathrm{Ti}_{3} \mathrm{C}_{2} \mathrm{~T}_{x}$ were the reasons for such improvements.

In summary, the toughness of ceramics can be improved by $2 \mathrm{D}$ nanomaterials, which can solve the brittleness problem. The strengthening of ceramic composites by 2D nanomaterials is mainly attributed to two reasons. The first reason is the microstructure of nanocomposites. The 2D nanomaterials are mainly dispersed at the grain boundaries of the ceramic matrices, resulting in a remarkable increase in the grain boundary strength and energy dissipation. Second, the outstanding intrinsic mechanical property and large surface area of 2D nanomaterials are equally important.

\subsubsection{Friction and wear characteristics}

As discussed in Section 4.1.2, very significant improvements have been achieved in ceramic matrices by using various types of 2D nanomaterials. Further research on the tribological performance of ceramics reinforced with 2D nanomaterials is necessary [161, 


\section{3-165, 178, 179].}

In a previous study by Belmonte et al. [178], graphene was added into a silicon nitride ceramic and the tribological properties of the graphene/ ceramic composite were reported. One of the most interesting properties of the graphene/ $\mathrm{Si}_{3} \mathrm{~N}_{4}$ composite is its excellent wear resistance, which can be attributed to the formation of a protective tribofilm by graphene. In addition, the tribological performance of zirconia composites reinforced with an in situ-reduced GO was reported recently [180]. The wear rate was decreased from $2.33 \times 10^{-5}$ to $4.66 \times 10^{-6} \mathrm{~mm}^{3} \cdot \mathrm{N}^{-1} \cdot \mathrm{m}^{-1}$ with $0.5 \mathrm{wt} \%$ GO (Fig. 11(a)). Moreover, various amounts of graphene were added into a ceramic to evaluate the friction and wear [181]. The results are interesting because all composites exhibited outstanding tribological performance, even those composites containing large amounts of graphene.

Besides graphene, other 2D nanomaterials including $\mathrm{BN}$ [28], $\mathrm{MoS}_{2}$ [182], and $\mathrm{WS}_{2}$ [183] have been incorporated into ceramic matrices by various fabrication methods. The results revealed that the tribological performance of ceramic composites is better than that of pure ceramics (Figs. 11(b) and 11(c)). These results verified the advantage of incorporating 2D nanomaterials in ceramic composites.

From the above discussion, it can be concluded that to obtain the lowest COF and best wear resistance, 2D nanomaterials can be considered as one of the most effective reinforcements (as listed in Table 5). The resulting microstructures of ceramic composites reinforced with 2D nanomaterials lead to significantly lower friction and wear [184]. The main wear mechanisms of ceramic composites reinforced with
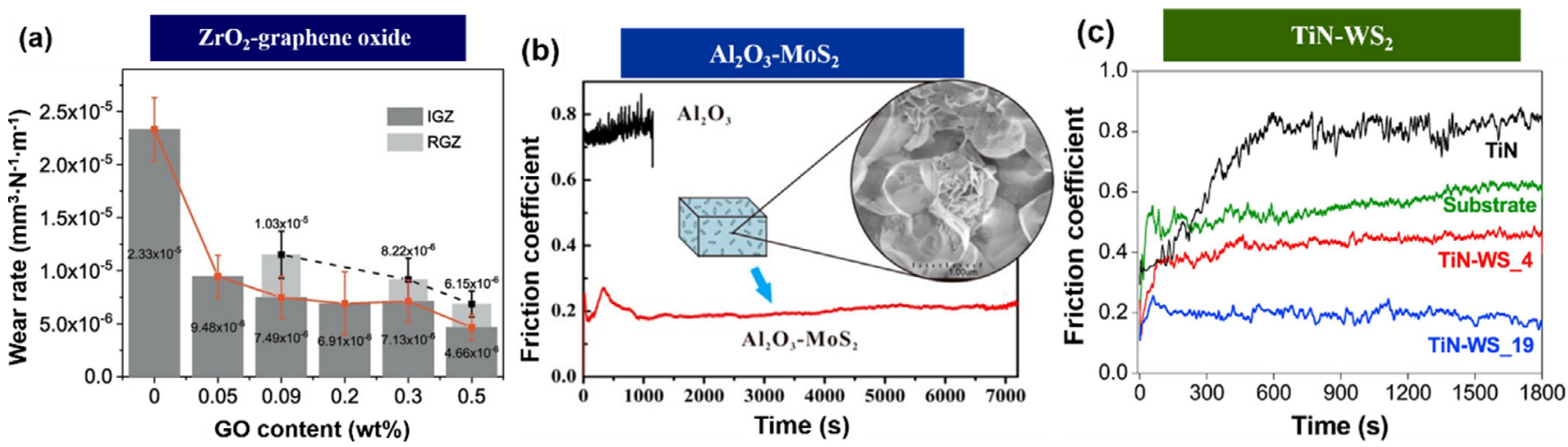

Fig. 11 (a) Specific wear rates of $\mathrm{ZrO}_{2}$ and $\mathrm{ZrO}_{2}-\mathrm{GO}$ (IGZ: in situ reduced graphene oxide reinforced 3 mol\% yttria stabilized zirconia; RGZ: Pre-reduced graphene oxide reinforced 3 mol\% yttria stabilized zirconia). Reproduced with permission from Ref. [180], (C) Elsevier Ltd. 2018. COFs of (b) $\mathrm{Al}_{2} \mathrm{O}_{3}$ and $\mathrm{Al}_{2} \mathrm{O}_{3}-\mathrm{MoS}_{2}$ composites. Reproduced with permission from Ref. [182], (C) American Chemical Society 2017. (c) TiN and TiN-WS ${ }_{2}$ composites. Reproduced with permission from Ref. [183], (C) Elsevier Ltd and Techna Group S.r.1. 2019.

Table 5 Tribological properties of ceramic composites reinforced with 2D materials.

\begin{tabular}{|c|c|c|c|c|c|c|}
\hline Matrix & 2D material & Method & Operating condition & $\mathrm{COF}$ & $\begin{array}{c}\text { Wear rate } \\
\left(\mathrm{mm}^{3} /(\mathrm{N} \cdot \mathrm{m})^{-1}\right) \\
\end{array}$ & Ref. \\
\hline $\mathrm{Al}_{2} \mathrm{O}_{3}$ & 1.0 vol\% graphene & $\begin{array}{l}\text { Ball milling and cold } \\
\text { isostatic press }\end{array}$ & $25 \mathrm{~N}, 0.1 \mathrm{~m} / \mathrm{s}$ & 0.35 & $2.0 \times 10^{-5}$ & {$[185]$} \\
\hline $\mathrm{Si}_{3} \mathrm{~N}_{4}$ & 20.6 vol\% graphene & Solution mixing and SPS & $\begin{array}{l}180 \mathrm{~N}, 0.1 \mathrm{~m} / \mathrm{s} \\
\text { lubrication with isooctane }\end{array}$ & 0.10 & $5.0 \times 10^{-8}$ & {$[181]$} \\
\hline $\mathrm{SiC}$ & 20 vol\% graphene & Solution mixing and SPS & $\begin{array}{l}180 \mathrm{~N}, 0.1 \mathrm{~m} / \mathrm{s} \\
\text { lubrication with isooctane }\end{array}$ & 0.12 & $1.0 \times 10^{-6}$ & [186] \\
\hline $\mathrm{ZrO}_{2}$ & $\begin{array}{c}0.5 \mathrm{wt} \% \\
\text { Graphene oxide }\end{array}$ & Ultrasonic and SPS & $30 \mathrm{~N}, 0.12 \mathrm{~m} / \mathrm{s}$ & 0.76 & $4.66 \times 10^{-6}$ & [180] \\
\hline $\mathrm{SiO}_{2}$ & 5.0 vol\% graphene & Ball milling and SPS & $5 \mathrm{~N}, 0.1 \mathrm{~m} / \mathrm{s}$ & 0.56 & $7.7 \times 10^{-6}$ & {$[179]$} \\
\hline $\mathrm{Si}_{3} \mathrm{~N}_{4}$ & $2.0 \mathrm{vol} \% \mathrm{BN}$ & Hot pressing & $39.2 \mathrm{~N}, 7.85 \mathrm{~mm} / \mathrm{s}$ & 0.30 & - & {$[28]$} \\
\hline $\mathrm{TiN}$ & $19 \mathrm{wt} \% \mathrm{WS}_{2}$ & $\begin{array}{l}\text { Reactive magnetron } \\
\text { sputtering }\end{array}$ & $2 \mathrm{~N}, 14 \mathrm{~mm} / \mathrm{s}$ & 0.19 & - & [183] \\
\hline $\mathrm{Al}_{2} \mathrm{O}_{3}$ & 10 vol $\% \mathrm{MoS}_{2}$ & $\begin{array}{l}\text { Ultrasonic and vacuum } \\
\text { infusing }\end{array}$ & $5 \mathrm{~N}, 5 \mathrm{~cm} / \mathrm{s}$, high vacuum & 0.20 & $1.4 \times 10^{-6}$ & [182] \\
\hline
\end{tabular}


2D nanomaterials are plastic deformation [180, 183] and microcracking [180]. These findings suggest that 2D nanomaterial-based ceramic composites have the potential for various tribological applications.

\subsection{Metal composites}

Metal composites are widely used in aerospace, automotive, precision instruments, and large infrastructure owing to their high strength and stiffness. Besides the well-designed 2D nanomaterialbased polymer and ceramic composites, 2D nanomaterials have also been used as reinforcements in metal matrices including Cu [99, 187-191], Al [192-194], $\mathrm{Mg}$ [195], Ni [91, 196], and alloys [197]. The mechanical properties of metal composites incorporating 2D nanomaterials are discussed in the following subsections.

\subsubsection{Strength}

Recent studies have shown that metal composites filled with 2D nanomaterials exhibit superior hardness, $Y$, compressive strength, and tensile strength at room temperature compared to their corresponding unreinforced matrices. For example, $\mathrm{Cu}$ /graphene composite is typical, as described in Refs. [198200]. Several recent studies reported the outstanding mechanical properties of composites with 2D nanomaterial contents from $0.05 \mathrm{wt} \%$ to $2 \mathrm{wt} \%$ [201]. However, the properties are highly dependent on the type and content of the 2D nanomaterial, as shown in Table 2.

The reinforcement of metal matrices using graphene has become one of the hottest topics in metal composite research $[44,45,77,81,91,92,99$, 187-189, 192, 193, 195, 196, 202-207]. Early studies on the mechanical properties of composites have demonstrated the advantages of incorporating graphene and its derivatives in metal composites [81, 194, 208-212]. The strengthening efficiency shown in Fig. 12 indicates that functionalized graphene can reinforce a copper matrix more effectively than other nanomaterials including carbon fiber, $\mathrm{CNT}$, and pristine graphene, leading to the best strengthening efficiency for metal matrices. To ensure uniform dispersion of graphene in the copper matrix, Shao et al. [49] fabricated graphene-

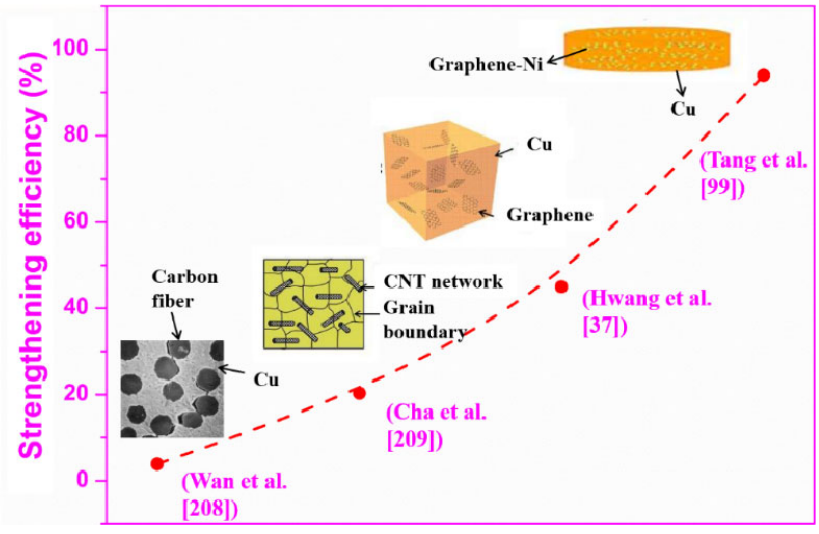

Fig. 12 Summary of progress in the strengthening efficiency of $\mathrm{Cu}$ matrix composites. Graphene-Ni. Reproduced with permission from Ref. [99], (C) Elsevier B.V. 2014. Carbon fiber. Reproduced with permission from Ref. [208], (C) Elsevier Science S.A. 2000. CNT network. Reproduced with permission from Ref. [209], C John Wiley and Sons 2005. Graphene. Reproduced with permission from Ref. [37], (C) John Wiley and Sons 2013.

nanoplatelets/copper (GNPs/Cu) composites by electrostatic self-assembly and spark plasma sintering. The resulting GNPs/Cu composite exhibited outstanding tensile strength and hardness. In another study, it was observed that the $\mathrm{Cu}-\mathrm{O}-\mathrm{C}$ bonding can be formed in graphene/Cu composites fabricated by electrochemical deposition [213]. Oxygen-mediated bonding was reported by Zhao [91], as depicted in Fig. 13. This suggests that interface bonding is important for achieving excellent mechanical properties in metal composites. Recently, the effects of ball milling time [93], content [214], and functional group [140] on the mechanical properties of metal composites have been studied in detail. Researchers are continuously extending the research scope of graphene/metal composites.

The addition of $\mathrm{BN}$ to a $\mathrm{Ni}_{3} \mathrm{Al}$ matrix has enhanced the elastic modulus and thereby shows its significant strengthening effect [36]. In another study, the enhancement in the mechanical properties of composites was attributed to the higher strength of the 2D nanomaterials [75]. Metal composites incorporating MXene or 2DMOF have not yet been explored owing to their high cost and expected defects in structure.

Five strengthening mechanisms are summarized here. First, dislocation strengthening occurs when 2D nanomaterials become effective barriers to dislocation migration [215, 216]. Molecular dynamics 

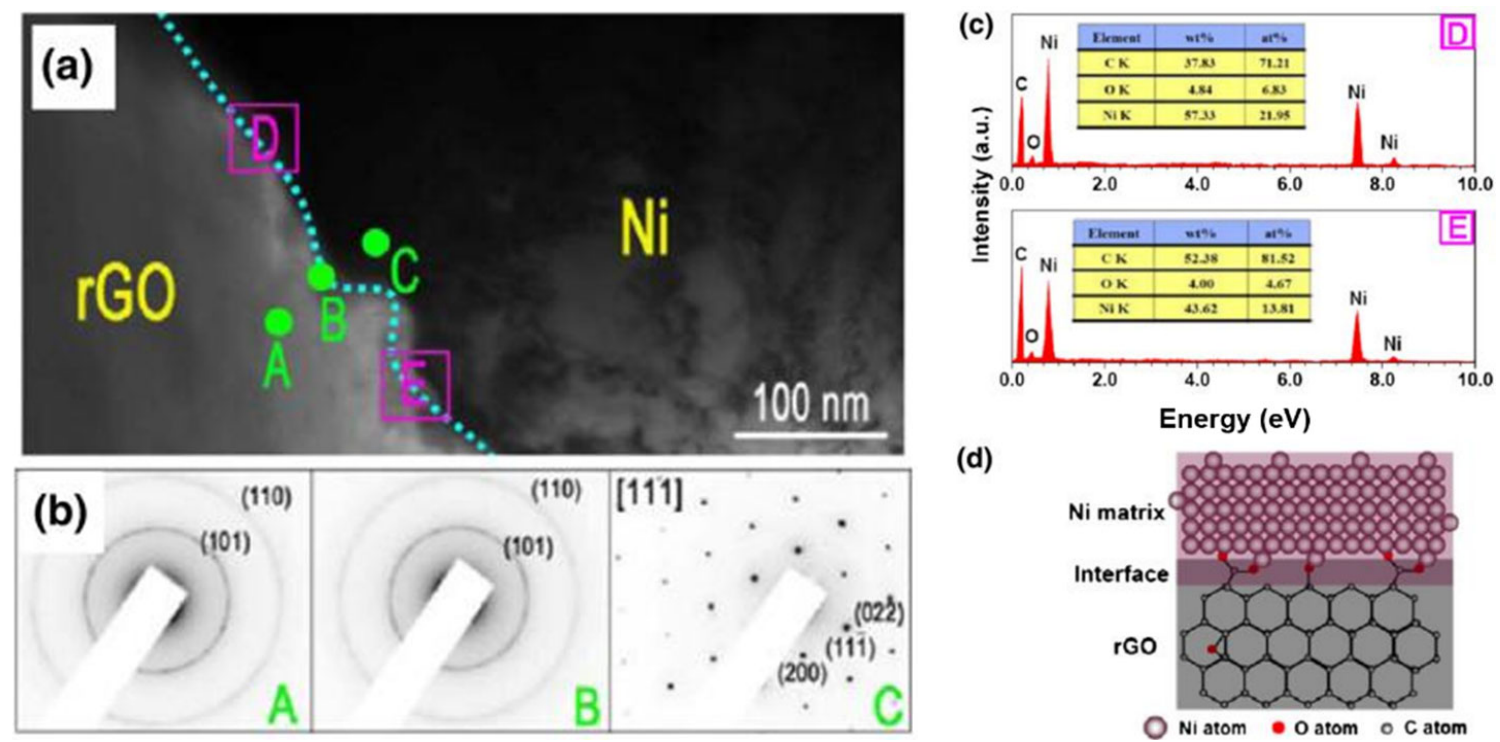

(d)

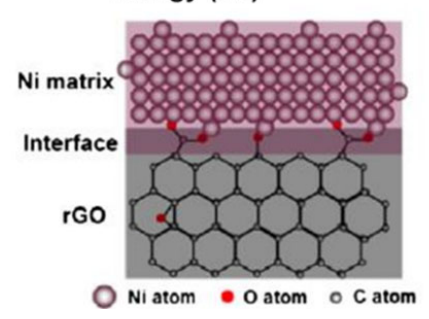

Fig. 13 (a) Transmission electron microscopy (TEM) image of the interface between rGO and Ni matrix. (b) Selected area electron diffraction patterns and (c) electron energy-dispersive X-ray spectrometry results at the regions marked in (a). (d) Schematic of interface bonding. Reproduced with permission from Ref. [91], C) Springer Nature 2014.

simulation results also corroborate this mechanism [217]. Second, it is generally accepted that load transfer can be achieved owing to the large surface area and high strength of 2D materials [204, 218]. Third, grain refinement in metal matrices also occurs as revealed by TEM [219]. In addition, thermal mismatch strengthening [211] and Orowan strengthening [36, 193] have been mentioned in some cases.

\subsubsection{Friction and wear characteristics}

The use of $2 \mathrm{D}$ nanomaterials to reinforce metals usually leads to excellent improvement in the selflubrication and anti-wear properties of the composites. The COF of $0.3 \mathrm{wt} \%$ graphene/ $\mathrm{Cu}$ composite decreases by $65 \%$ compared to that of pure copper [220]. Graphene addition causes a plastic zone and a decrease in grain size [45]. It is noteworthy that as a 2D-layered nanomaterial, graphene has a lubricating effect [221], leading to a fairly stable frictional behavior in metal composites [197]. Moreover, the excellent antifriction performance of graphene has been revealed by both simulation and experimental studies [13]. BN-reinforced $\mathrm{Ni3} A l$ composites also showed outstanding lubrication and anti-wear resistance [36]. Compared to metal composites reinforced with graphene, those reinforced with $\mathrm{BN}$ exhibit high COF and poor wear resistance. This is because graphene possesses better self-lubrication characteristics [220].
Mai et al. [222] first demonstrated that MXenes can significantly improve the tribological properties of metal matrix composites. However, different from other 2D nanomaterials such as graphene, it is difficult to observe transfer layers on the contact surface of the $\mathrm{Ti}_{3} \mathrm{C}_{2} / \mathrm{Cu}$ composite. Thus, the lack of transfer layers is one of the major reasons for its poor tribological properties. Therefore, it is worthwhile to carry out further research on how to improve this aspect in the future.

The above discussions show that the COF and wear rate of metal composites decrease with the addition of 2D nanomaterials. This improved tribological performance is mainly attributed to the formation of a tribolayer on the contacting surfaces [223-227]. Table 6 summarizes typical data on the tribological properties of metal composites reinforced with $2 \mathrm{D}$ materials.

\section{Salient factors influencing the per- formance of composites}

The enhancement in the mechanical and tribological properties of composites by 2D nanomaterial reinforcement also depends on numerous factors such as aspect ratio, volume fraction of nanomaterials, orientation of nanosheet, and interface bonding between the filler and matrix [230]. Naturally, the 
Table 6 Tribological properties of metal composites reinforced with 2D materials.

\begin{tabular}{|c|c|c|c|c|c|c|}
\hline Matrix & 2D material & Method & $\begin{array}{l}\text { Operating } \\
\text { condition }\end{array}$ & $\mathrm{COF}$ & $\begin{array}{c}\text { Wear rate } \\
\left(\mathrm{mm}^{3} /(\mathrm{N} \cdot \mathrm{m})^{-1}\right)\end{array}$ & Ref. \\
\hline TiAl & $3.5 \mathrm{wt} \%$ graphene & SPS & $10 \mathrm{~N}, 0.2 \mathrm{~m} / \mathrm{s}$ & 0.33 & $0.33 \times 10^{-4}$ & [197] \\
\hline $\mathrm{Ni}_{3} \mathrm{Al}$ & $1.0 \mathrm{wt} \%$ graphene & Ball milling and SPS & $11.65 \mathrm{~N}, 1.0 \mathrm{~m} / \mathrm{s}$ & 0.20 & $9.0 \times 10^{-6}$ & {$[228]$} \\
\hline $\mathrm{Ni}_{3} \mathrm{Al}$ & $\mathrm{BN}$ & $\begin{array}{l}\text { Selective laser } \\
\text { melting }\end{array}$ & $9 \mathrm{~N}$ & 0.22 & $2.1 \times 10^{-5}$ & {$[36]$} \\
\hline $\mathrm{Cu}$ & 10 vol $\%$ graphene & Hot pressing & $2 \mathrm{~N}, 1 \mathrm{~m} / \mathrm{s}$ & 0.17 & $1.8 \times 10^{-4}$ & {$[229]$} \\
\hline $\mathrm{Cu}$ & 4.0 vol\% graphene & $\begin{array}{l}\text { Molecular level } \\
\text { mixing and SPS }\end{array}$ & $5 \mathrm{~N}, 0.01 \mathrm{~m} / \mathrm{s}$ & 0.25 & - & {$[45]$} \\
\hline $\mathrm{Cu}$ & 2 wt\% Ni@graphene & $\begin{array}{l}\text { Ball-milling and } \\
\text { hot-pressing }\end{array}$ & $6 \mathrm{~N}, 0.105 \mathrm{~m} / \mathrm{s}$ & 0.2 & $0.1 \times 10^{-3}$ & [224] \\
\hline $\mathrm{Cu}$ & Graphene & $\begin{array}{c}\text { Ambient-pressure } \\
\text { CVD }\end{array}$ & $1 \mathrm{~N}, 2.74 \mathrm{~cm} / \mathrm{s}$ & 0.2 & $2.8 \times 10^{-5}$ & [223] \\
\hline $\mathrm{Cu}$ & $\mathrm{Ti}_{3} \mathrm{C}_{2}$ & $\begin{array}{l}\text { Electrodeposition } \\
\text { Technique }\end{array}$ & $1 \mathrm{~N}, 5.2 \mathrm{~cm} / \mathrm{s}$ & 0.27 & $3.7 \times 10^{-5}$ & {$[222]$} \\
\hline $\mathrm{Ni}$ & $0.68 \mathrm{wt} \%$ graphene & Powder metallurgy & $5 \mathrm{~N}, 9 \mathrm{~mm} / \mathrm{s}$ & 0.39 & $5 \times 10^{-4}$ & {$[225]$} \\
\hline $\mathrm{Al}$ & $2 \mathrm{wt} \% \mathrm{WS}_{2}$ & Cold spray & $1 \mathrm{~N}, 2 \mathrm{~mm} / \mathrm{s}$ & 0.6 & $88 \times 10^{-3}$ & {$[227]$} \\
\hline Al & 10 vol $\%$ graphene & Powder metallurgy & $10 \mathrm{~N}, 0.1 \mathrm{~m} / \mathrm{s}$ & 0.2 & $9 \times 10^{-3}$ & {$[226]$} \\
\hline $\mathrm{Al}$ & 15 vol $\% \mathrm{MoS}_{2}$ & Powder metallurgy & $10 \mathrm{~N}, 0.1 \mathrm{~m} / \mathrm{s}$ & 0.2 & $20 \times 10^{-3}$ & {$[226]$} \\
\hline $\mathrm{Al}$ & 15 vol $\% \mathrm{BN}$ & Powder metallurgy & $10 \mathrm{~N}, 0.1 \mathrm{~m} / \mathrm{s}$ & 0.4 & $100 \times 10^{-3}$ & {$[226]$} \\
\hline
\end{tabular}

improvement in mechanical properties depends on various factors including the matrix, reinforcement, and process. These influencing factors in the context of the mechanical properties of 2DNBCs are discussed as follows.

\subsection{Matrix type}

As is well known, there are many types of matrix materials that can be selected. It is also essential to emphasize that the mechanical properties of composites fundamentally depend on the matrix [231]. Commonly, the order of the magnitude of tensile strength is ceramic matrix $>$ metal matrix $>$ polymer matrix. After being reinforced by 2D nanomaterials, the tensile strength of composites maintains a similar trend, as displayed in Fig. 14. In addition, the order of the magnitude of elastic modulus is similar (ceramics: $30-1,000 \mathrm{GPa}$; metals: 50-300 GPa; polymers: 0.4-4.0 GPa). Further, different varieties of the same type of material also exhibit different mechanical performances owing to differences in the chemical composition and structure.

\subsection{Reinforcement state}

In the previously highlighted key points, the majority of the effects on the mechanical properties were attributed primarily to the physical properties of 2D nanomaterials (Fig. 15). The synergistic effect of graphene with other 2D nanomaterials was also reported by many researchers. Previous AFM-based indentation experiments have also demonstrated its significance [65].

\subsubsection{Geometry}

The geometry of 2D nanomaterials, such as lateral dimension, thickness, and aspect ratio, determines its mechanical properties. A key factor that affects many properties including mechanical properties is the lateral dimension [29]. 2D nanomaterials have a layered structure with a large lateral dimension and atomic thickness. Khan et al. [240, 241] found that the mean sizes of graphene and $\mathrm{MoS}_{2}$ nanosheets have evident effects on the mechanical properties of composites. The high aspect ratio of BN sheets is a critical factor for improving the mechanical property of a composite [86]. The macromolecular chains of the matrix are confined by $2 \mathrm{D}$ nanomaterials with a high aspect ratio. The effect has also been confirmed in graphene/PEEK [43]. 


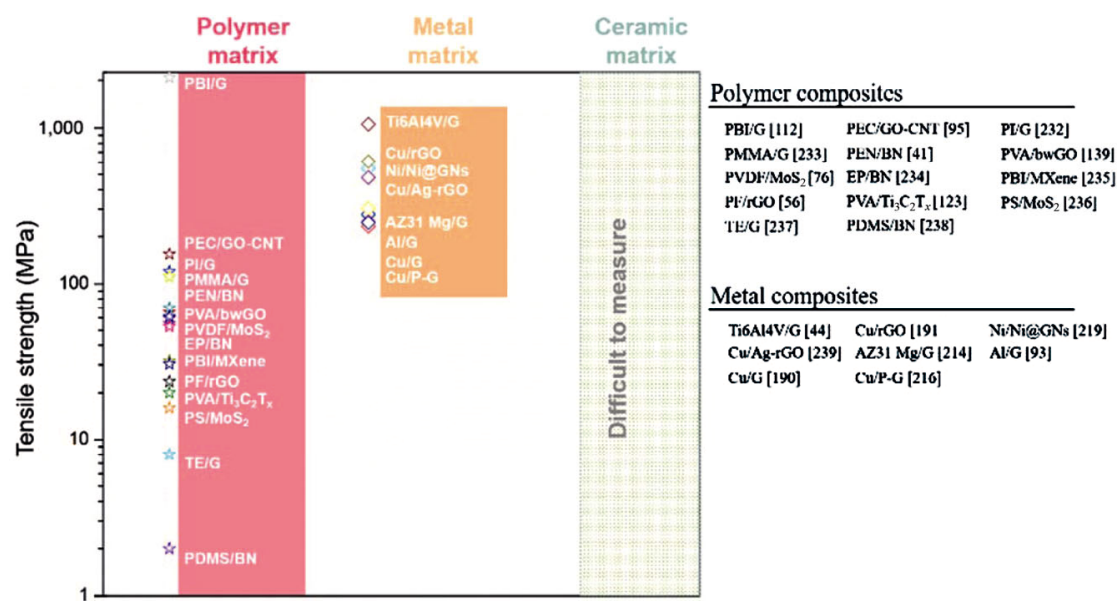

Fig. 14 Comparison of various matrices incorporating 2D materials (PBI: polybenzimidazole; PS: polystyrene; TE: thermoplastic elastomers; PDMS: polydimethylsiloxane; bwGO: base-washed graphene oxide; P-G: plasma treated graphene).

(a)

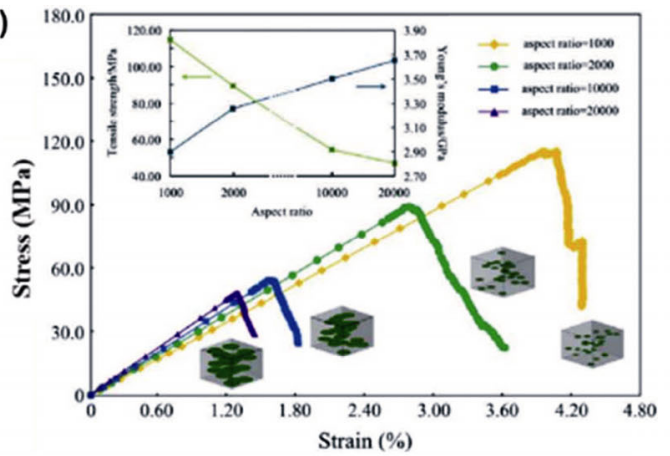

(c)

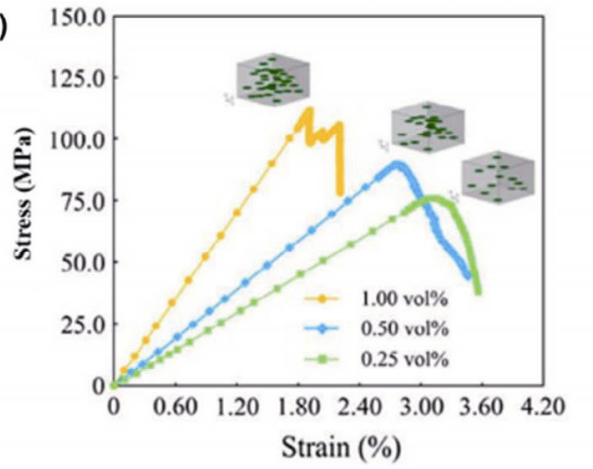

(b)

(d)

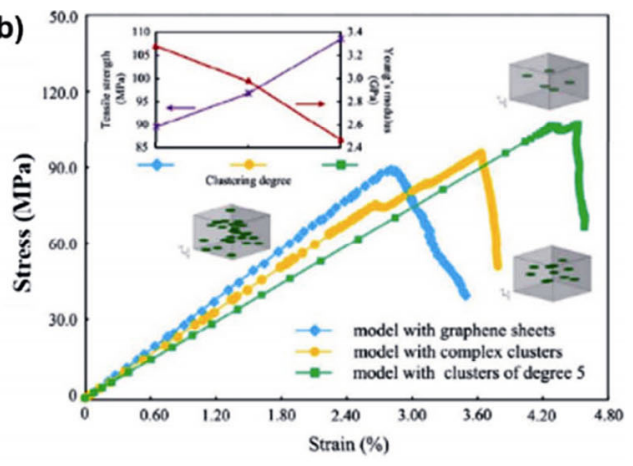

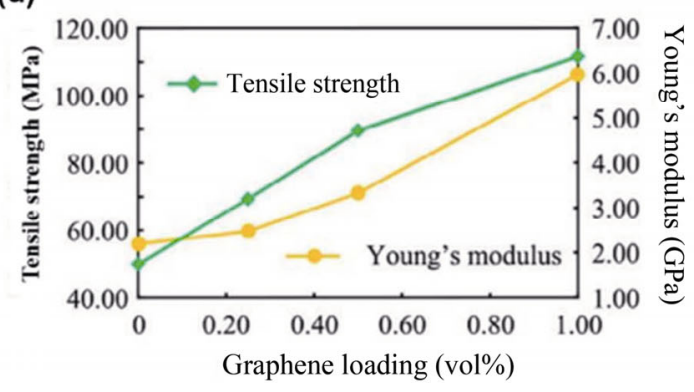

(e)

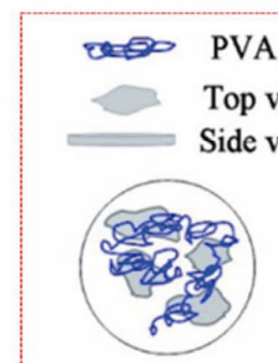

(1)

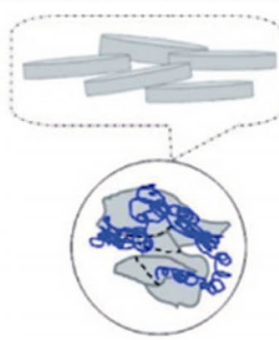

(3)

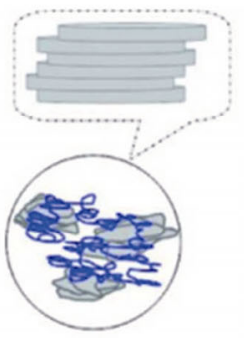

(4)

(2)

Loading of graphene

High

Fig. 15 Effect of (a) aspect ratio, (b) dispersion, and (c, d) volume content of graphene on the strain-stress curves of nanocomposites. Reproduced with permission from Ref. [63], C) Elsevier B.V. 2014. (e) Schematic of the effect of volume content on the microstructure. Reproduced with permission from Ref. [55], (C) American Chemical Society 2010. 
Moreover, thickness plays an important role in the mechanical properties of composites. Kiran et al. [79] demonstrated that the mechanical properties decrease linearly with increasing number of $\mathrm{BN}$ layers. Furthermore, several researchers reported the effect of thickness on wear of graphene/PTFE composites [148]. The results revealed the relation between wear and thickness.

When the 2D nanomaterials are small and thin, the composites have high tensile strength and ductility [242, 243]. These results demonstrate that the mechanical properties of polymer composites containing 2D nanomaterials depend primarily on the number of layers, with the properties decreasing linearly with increasing number of layers.

Although the aspect ratio plays a crucial role in determining the composite properties, little attention has been given to its influence on the mechanical and tribological properties of composites. A large aspect ratio can promote the load transfer ability in composite systems [236].

\subsubsection{Volume content}

The volume content of $2 \mathrm{D}$ nanomaterials is a key factor in controlling the mechanical strength, COF, and wear rate [45, 244, 245]. An extremely small amount of 2D nanomaterial, usually no more than $5 \mathrm{wt} \%$, can significantly improve the mechanical properties of composites. As indicated in Fig. 15(e), the microstructure of a polymer composite has changed remarkably as the volume content of graphene increases. With the high volume content of graphene, the original advantage of a layered structure disappears, resulting in the deterioration of the mechanical properties.

The tensile strength of a composite can be calculated as [49]

$$
\sigma_{\mathrm{c}}=\sigma_{\mathrm{g}} V_{\mathrm{g}}+\left(1-V_{\mathrm{g}}\right) \sigma_{\mathrm{m}}
$$

where $\sigma_{\mathrm{g}}, \sigma_{\mathrm{m}}$, and $\sigma_{\mathrm{c}}$ are the tensile strength of graphene, the matrix, and the composite, respectively; whereas $V_{\mathrm{g}}$ represents the volume content of graphene. It may be noted that the volume content is crucial to the tensile strength of composites. As mentioned above, there is a critical point of the volume content [56]. At the critical point, the composite exhibits the best mechanical property
[246]. The strength and modulus of composites both increase with the increase in the 2D nanomaterial content [63]. At a higher volume content, 2D nanomaterials are prone to self-aggregation, resulting in the deterioration of the mechanical properties of the composite [41].

\subsubsection{Dispersion}

The effect of the dispersion of 2D nanomaterials on the mechanical properties of 2DNBCs has been extensively studied [6, 47, 121, 160, 218, 247-249]. To summarize, the degree of dispersion, including that of the 2D nanomaterials and other fillers, has a significant impact on the mechanical performance of composites. Figure 15(b) illustrates the effect of dispersion of graphene on the strain-stress curves of nanocomposites. Poor dispersion decreases the effective aspect ratio of 2D nanomaterials, leading to the deterioration in mechanical properties. Thus, dispersion is a major challenge in the fabrication of various composites [250]. Luo et al. [239] found that homogeneous dispersion of graphene can be achieved by the modification of silver nanoparticles. All the aspects mentioned above suggest that dispersion is one of the key factors for improving the mechanical properties. Achieving effective dispersion of $2 \mathrm{D}$ materials in the matrix should therefore be explored further.

\subsubsection{Orientation}

Recent studies have examined the role of the orientation of 2D nanomaterials within a material in its mechanical and tribological properties [234, 251]. A well-ordered orientation of 2D nanomaterials in composites maximizes the interactions between the 2D nanomaterials and the matrices, which lead to efficient stress transfer [252]. Conversely, a random distribution of 2D nanomaterials causes low load transfer ability [253]. Li et al. [251] reported that the Krenchel orientation factor can predict the effect of spatial orientation on the mechanical properties of 2DNBCs. Jan et al. [254] found that improving the alignment of $\mathrm{BN}$ nanosheets by uniaxial drawing can enhance the mechanical properties of composites. To control the orientation of graphene and its derivatives, a previous review 
summarized a series of methods and evaluated the resulting properties [255].

\subsubsection{Interface bonding}

Interface bonding comprises hydrogen bonding, covalent bonding, ionic interactions, electrostatic interactions, and so on. Most studies have mentioned that interface bonding is an important factor to be considered [232, 256-258], as displayed in Fig. 16. Under axial stress, the parallel lines become distorted owing to the low $Y$ of the matrix (Fig. 16(g)). This means that $2 \mathrm{D}$ nanomaterials carry most of the
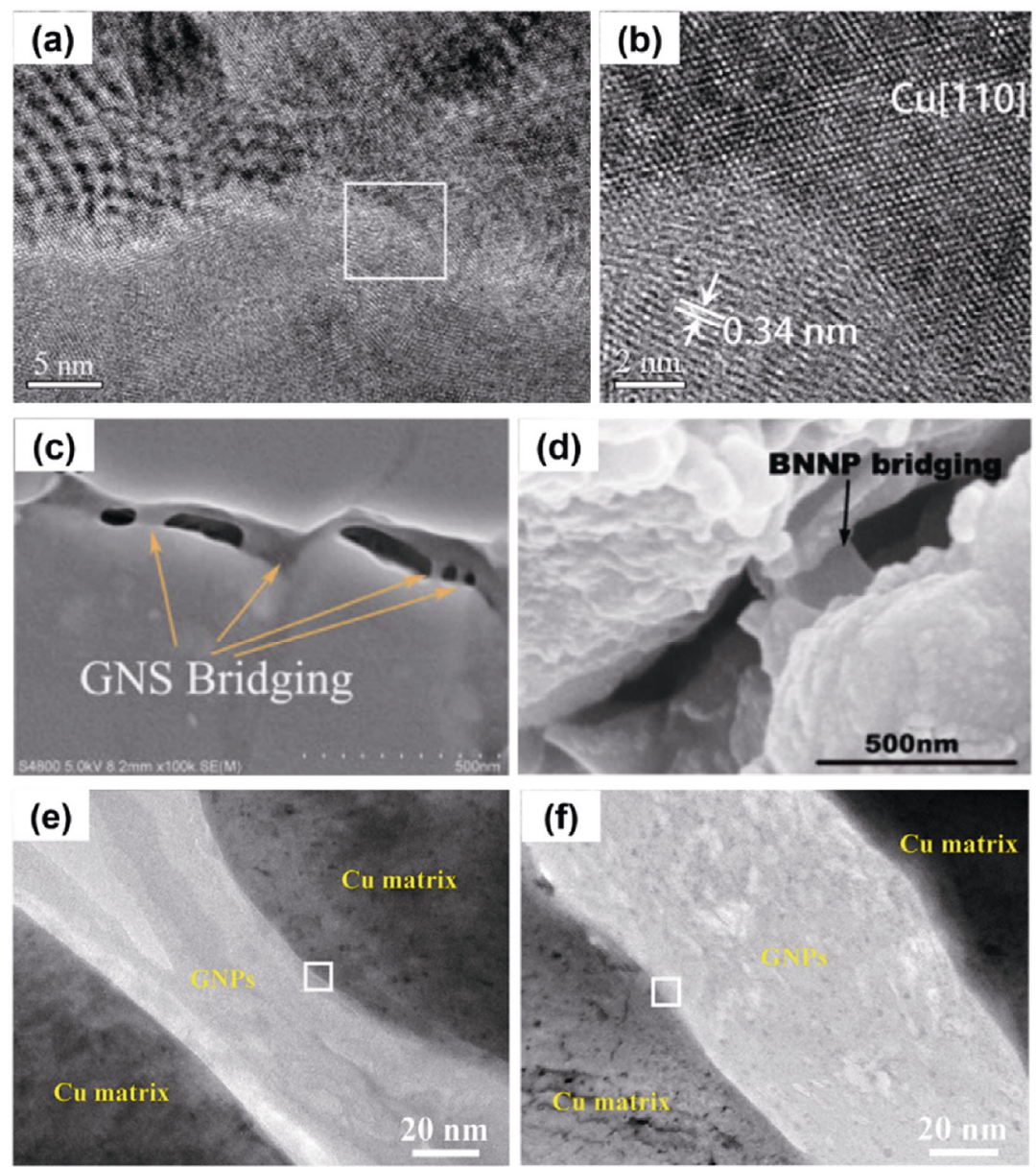

(g)

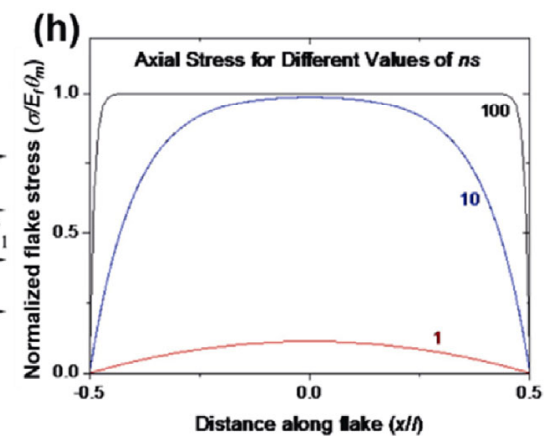

Fig. 16 Typical interface between graphene and copper matrix: $(a, b)$ the interplanar distance of graphene is $0.34 \mathrm{~nm}$. Reproduced with permission from Ref. [204], (c) American Chemical Society 2015. Bridging of 2D materials in composite systems: (c) graphene bridging. Reproduced with permission from Ref. [166], (c) Elsevier Ltd and Techna Group S.r.1. 2015. (d) BN bridging. Reproduced with permission from Ref. [36], (c) The Authors 2019. (e, f) Graphene bridging. Reproduced with permission from Ref. [49], () Elsevier B.V. 2018. (g, h) Deformation patterns of 2D material in a matrix under axial stress $\sigma_{1}$. Reproduced with permission from Ref. [126], (C) The Authors 2017. 
load in the composite. According to the elastic contact theory [259], the $Y$ of the matrix will be affected by the interfacial contact between the 2D nanomaterial and matrix. To ensure adequate stress transfer, strong interface bonding between the 2D nanomaterial and matrix is essential. In view of the importance of interface bonding, the interface microstructure was investigated by TEM in Ref. [49]. The 2D nanomaterial was incorporated into composites, resulting in the presence of $2 \mathrm{D}$ bridging.

Interface bonding can be controlled by modification [2, 130] and ball milling [93]. As the interface bonding is improved, the final $Y$ of the composite becomes almost three times higher than that of the pure matrix [2]. Thus, the design of the interface is essential owing to its importance in suppressing shear bands of the composites. It is also called interface-dominated/enabled mechanical behavior [260]. In addition to its use as enhancement fillers in composites, 2D nanomaterials have proved to be an efficient potent coupling agent [261]. Ultrathin GO was introduced in the interface between silica and EP resin to optimize the mechanical properties [262]. The results showed that the mechanical reinforcement is superior compared to those reported by others. $\mathrm{Ti}_{3} \mathrm{C}_{2} \mathrm{~T}_{x}$ MXene nanosheets are already used for enhancing the interfacial connection between carbon fibers and EP resins as well as for reducing the stress concentration of the interface [101]. The design might be complicated, but it has the great advantage of improving the tensile, flexural, shear, and impact strengths.

\subsection{Processing parameters}

Composites fabricated by different methods may possess different mechanical properties. In fact, there are many processing parameters in every method, such as pressure, temperature, and time. As described in Section 2, the main methods used for fabricating 2DNBCs are in situ polymerization, solution mixing, melt blending, powder metallurgy, reaction bonding, chemical vapor deposition/ infiltration, and molecular-level mixing. Additionally, novel approaches of fabricating advanced composites [263] have been developed. Each processing parameter directly affects the quality of the composites and even creates defects. Thus, the mechanical properties of composites are affected significantly by the processing parameters.

\section{Potential applications}

In Section 4 , the mechanical properties of 2DNBCs are reviewed. Excellent mechanical properties can lead to more applications and reduced costs of composites. In this section, we will focus on the discussion about the potential of the aforementioned prepared composites for a number of applications based on their outstanding mechanical properties (Fig. 17).

\subsection{Aviation and aerospace}

Composites have been used for a long time and

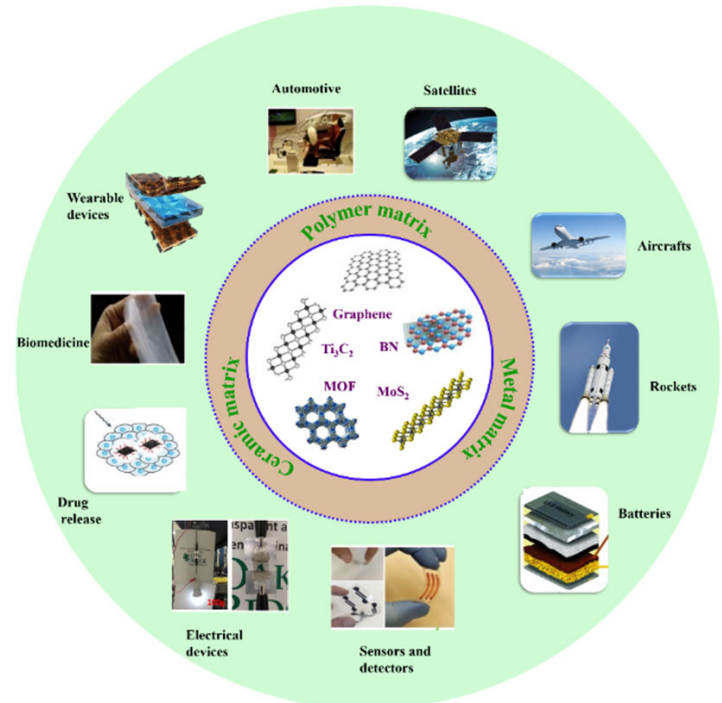

Fig. 17 Advanced technological applications of 2DNBCs. $\mathrm{Ti}_{3} \mathrm{C}_{2}$. Reproduced with permission from Ref. [264], (C) John Wiley and Sons 2014. BN. Reproduced with permission from Ref. [265], (C) John Wiley and Sons 2018. $\mathrm{MoS}_{2}$. Reproduced with permission from Ref. [266], (C) American Chemical Society 2017. MOF. Reproduced with permission from Ref. [267], (C) John Wiley and Sons 2015. Drug release. Reproduced with permission from Ref. [268], (C) Springer Nature 2017. Wearable devices. Reproduced with permission from Ref. [269], (C) American Chemical Society 2018. Electrical devices. Reproduced with permission from Ref. [270], (C) American Chemical Society 2015. Biomedicine, automotive, sensors, and detectors. Reproduced with permission from Ref. [271], (C) Elsevier B.V. 2016. Batteries. Reproduced with permission from Ref. [272], (C) Science China Press 2017. 
have become important materials in the field of aviation and aerospace. To further improve their performance, studies on reinforcing them with 2DNBCs have been reported widely in the literature. Among the family of 2DNBCs, graphene-based nanocomposites are one of the most promising materials in view of their excellent specific strength and good wear resistance. Besides graphene-based nanocomposites, composites incorporating $\mathrm{MoS}_{2}$ and $\mathrm{BN}$ also exhibit excellent tribological properties. The different types of applications in aviation and aerospace can be categorized into structural components, e.g., fuselages, wings, and moving components, such as bearings, gears, and hatch seals [34]. It is well known that the aviation and aerospace industry depends on many structural and moving machine components; thus, 2DNBCs will play significant roles in this industry.

\subsection{Biomedicine}

The biomedical applications of 2DNBCs mainly include tissue engineering scaffolds [15, 273], drug delivery [274], thermotherapy [269, 275], and biosensors [276, 277]. Effective drug loading can be achieved by $2 \mathrm{DNBC}$ s owing to the $2 \mathrm{D}$ structure and delocalized surface $\pi$ electrons [274]. Thus, composites have potential applications in drug delivery systems. Commonly, polymer composites used in tissue engineering scaffolds usually require structural strength and support [273]. To enhance their mechanical properties, 2D nanomaterials such as graphene and GO are incorporated into these matrices. For instance, Das et al. [65] demonstrated that incorporating functionalized few-layer graphene into PVA and PMMA can significantly increase their hardness and elastic modulus.

\subsection{Energy storage}

Energy storage including supercapacitors and batteries is a hot research area [278]. Based on the ultrathin flexible 2D structure, 2DNBCs applied to supercapacitors can endure different mechanical deformations [272]. For example, the graphene/polymer has led to successful implementation in supercapacitor [279]. In this case, graphene provided the most effective flexibility.
MXene/PVA composite has been used as electrode for supercapacitors and exhibits impressive performance [280]. It is noted that MXene provides an excellent flexibility and then the composite can sustain 5,000 times its own weight. In addition, 2DNBCs have potential to be used as protection materials and barrier materials such as body armor, ambient armor due to the in-plane mechanical isotropy of the 2D nanomaterial. Its critical penetration velocity gives 2DNBC a unique advantage over traditional woven fabric [281].

Overall, the potential application of 2DNBCs will be further expanded with the development of study of 2D nanomaterial [282]. It will have to be recognized that more work is needed in order to realize the true potential of $2 \mathrm{DNBCs}$ and to explore new application in the future.

\section{Conclusions}

In recent years, there has been a rapid development in the field of composites, especially in the design and characterization of novel 2DNBCs. Here, various characterization methods, including the use of universal testing machine, tribological testing, DMA, nanoindentation, and AFM, are introduced. All of these methods are proposed for the measurement of the mechanical and tribological properties of composites. Compared with conventional methods, microscopic methods, such as AFM, nanoindentation, and theoretical calculations, are becoming more important. This review reports the recent progress pertaining to the mechanical and tribological properties of composites reinforced with different 2D nanomaterials. Such nanomaterials including graphene, GO, rGO, phosphorene, $\mathrm{BN}$, g- $\mathrm{C}_{3} \mathrm{~N}_{4}, \mathrm{MoS}_{2}, \mathrm{WS}_{2}, \mathrm{Ti}_{3} \mathrm{C}_{2} \mathrm{~T}_{x}$, and MOF can effectively enhance the properties of composites because of their distinctive characteristics that can result in uniform dispersion, optimized orientation, and strong interface bonding. Of these 2D nanomaterials, graphene has been studied the most because of its ultrahigh strength, relatively low cost, and mature technology. In addition, owing to the weak interlayer van der Waals interaction of 2D nanomaterials, composites possessing outstanding tribological properties such 
as ultralow friction, self-lubricating action, and ultralow wear rate can be realized. For these reasons, 2D nanomaterials are considered as the best reinforcements for various composites, such as polymers, ceramics, and metals. Particularly, the intrinsic mechanical properties of graphene have been proven to be excellent and it has been widely used for reinforcing various matrices. Further, the functionalization of 2D nanomaterials will be an effective approach for strengthening the interface bonding between the matrix and reinforcement.

Despite the enormous advances, several problems of 2DNBCs have not been fully resolved yet. These challenges include the followings:

1) Preparation of tailored 2D nanomaterials. Though much progress has been made in the preparation of 2D nanomaterials, high-quality and single-layer 2D nanomaterials except for graphene are still lacking. This is one of the main challenges in this field.

2) Uniform distribution of $2 D$ nanomaterials in matrices. This determines the strength of the interface between the matrix and the 2D nanomaterial. Some easy and effective approaches are still expected. In addition, optimal orientation of the 2D nanomaterial needs to be maintained as much as possible by an appropriate technology such as external electric fields and magnetic fields.

3) Fundamental mechanism of strengthening and tribology for various composite systems. Much research has been attempted to elucidate the fundamental mechanism. However, some new systems such as phosphorene/polymer and MXene/polymer have not been investigated.

4) Low-cost applications of 2DNBCs. An increasing number of composite materials are being developed; thus, it is necessary to consider their particular applications. The cost and scalability should also be taken into consideration for real applications.

Considering the importance of composites for human activities, effectively designing and fabricating 2DNBCs need to be addressed in the future. This review opens up a new path toward the design of advanced composites having potential applications in various technological systems.

\section{Acknowledgements}

The authors gratefully acknowledge the financial support from the National Natural Science Foundation of China (Grant No. 51822505), Major Scientific Research and Development Project in Jiangxi (Grant No. 20173ABC28008), Tsinghua University Initiative Scientific Research Program (Grant No. 2019Z08QCX11), and Beijing Natural Science Foundation of China (Grant No. 3182010). The authors thank Dr. Jie CHENG, Feng HE, Dr. Xiao YANG, Zhendong LIAO, and Guangzhi XIONG for their invaluable contributions to this collaboration.

Open Access This article is licensed under a Creative Commons Attribution 4.0 International License, which permits use, sharing, adaptation, distribution and reproduction in any medium or format, as long as you give appropriate credit to the original author(s) and the source, provide a link to the Creative Commons licence, and indicate if changes were made.

The images or other third party material in this article are included in the article's Creative Commons licence, unless indicated otherwise in a credit line to the material. If material is not included in the article's Creative Commons licence and your intended use is not permitted by statutory regulation or exceeds the permitted use, you will need to obtain permission directly from the copyright holder.

To view a copy of this licence, visit http://creativecommons.org/licenses/by/4.0/.

\section{References}

[1] Stankovich S, Dikin D A, Dommett G H B, Kohlhaas K M, Zimney E J, Stach E A, Piner R D, Nguyen S B T, Ruoff R S. Graphene-based composite materials. Nature 442(7100): 282-286 (2006)

[2] Ramanathan T, Abdala A A, Stankovich S, Dikin D A, Herrera-Alonso M, Piner R D, Adamson D H, Schniepp H C, Chen X, Ruoff R S, et al. Functionalized graphene sheets for polymer nanocomposites. Nat Nanotechnol 3: 327-331 (2008)

[3] Huang X, Qi X Y, Boey F, Zhang H. Graphene-based composites. Chem Soc Rev 41(2): 666-686 (2012)

[4] Kim S, Wang H T, Lee Y M. 2D nanosheets and their composite membranes for water, gas, and ion separation. Angew Chem Int Ed Engl 58(49): 17512-17527 (2019) 
[5] Li X, Sun M, Shan C X, Chen Q, Wei X L. Mechanical properties of $2 \mathrm{D}$ materials studied by in situ microscopy techniques. Adv Mater Interfaces 5(5): 1701246 (2018)

[6] Baig Z, Mamat O, Mustapha M. Recent progress on the dispersion and the strengthening effect of carbon nanotubes and graphene-reinforced metal nanocomposites: A review. Crit Rev Solid State Mater Sci 43(1): 1-46 (2018)

[7] Lee C, Wei X D, Kysar J W, Hone J. Measurement of the elastic properties and intrinsic strength of monolayer graphene. Science 321(5887): 385-388 (2008)

[8] Wang W, Xie G X, Luo J B. Black phosphorus as a new lubricant. Friction 6(1): 116-142 (2018)

[9] Naguib M, Kurtoglu M, Presser V, Lu J, Niu J J, Heon M, Hultman L, Gogotsi Y, Barsoum M W. Two-dimensional nanocrystals produced by exfoliation of $\mathrm{Ti}_{3} \mathrm{AlC}_{2}$. $A d v$ Mater 23(37): 4248-4253 (2011)

[10] Halim J, Kota S, Lukatskaya M R, Naguib M, Zhao M Q, Moon E J, Pitock J, Nanda J, May S J, Gogotsi Y, et al. Synthesis and characterization of 2D molybdenum carbide (MXene). Adv Funct Mater 26(18): 3118- 3127 (2016)

[11] Hong Ng V M, Huang H, Zhou K, Lee P S, Que W X, $\mathrm{Xu} \mathrm{J}$ Z, Kong L B. Recent progress in layered transition metal carbides and/or nitrides (MXenes) and their composites: Synthesis and applications. J Mater Chem A 5(7): 3039-3068 (2017)

[12] Dai W Y, Shao F, Szczerbiński J, McCaffrey R, Zenobi R, Jin Y H, Schlüter A D, Zhang W. Synthesis of a twodimensional covalent organic monolayer through dynamic imine chemistry at the air/water interface. Angew Chem Int Ed Engl 55(1): 213-217 (2016)

[13] Liu L C, Zhou M, Jin L, Li L C, Mo Y T, Su G S, Li X, Zhu $\mathrm{H}$ W, Tian Y. Recent advances in friction and lubrication of graphene and other 2D materials: Mechanisms and applications. Friction 7(3): 199-216 (2019)

[14] Sha Z D, Pei Q X, Ding Z W, Jiang J W, Zhang Y W. Mechanical properties and fracture behavior of singlelayer phosphorene at finite temperatures. J Phys D: Appl Phys 48(39): 395303 (2015)

[15] Shuai C J, Sun H, Gao C D, Feng P, Guo W, Yang Y, Zhao M C, Yang S, Yuan F L, Peng S P. Mechanical reinforcement of bioceramics scaffolds via fracture energy dissipation induced by sliding action of $\mathrm{MoS}_{2}$ nanoplatelets. J Mech Behav Biomed Mater 75: 423- 433 (2017)

[16] Bertolazzi S, Brivio J, Kis A. Stretching and breaking of ultrathin $\mathrm{MoS}_{2}$. ACS Nano 5(12): 9703-9709 (2011)

[17] Zhi C Y, Bando Y, Tang C C, Kuwahara H, Golberg D. Large-scale fabrication of boron nitride nanosheets and their utilization in polymeric composites with improved thermal and mechanical properties. Adv Mater 21(28): 2889-2893 (2009)

[18] Jiang J W, Park H S. Mechanical properties of single- layer black phosphorus. J Phys D: Appl Phys 47(38): 385304 (2014)

[19] Pang J B, Mendes R G, Bachmatiuk A, Zhao L, Ta H Q, Gemming T, Liu H, Liu Z F, Rummeli M H. Applications of 2D MXenes in energy conversion and storage systems. Chem Soc Rev 48(1): 72-133 (2019)

[20] Hermosa C, Horrocks B R, Martínez J I, Liscio F, Gó mez-Herrero J, Zamora F. Mechanical and optical properties of ultralarge flakes of a metal-organic framework with molecular thickness. Chem Sci 6(4): 2553-2558 (2015)

[21] Li D, Kaner R B. Graphene-based materials. Science 320(5880): 1170-1171 (2008)

[22] Kim H, Abdala A A, Macosko C W. Graphene/polymer nanocomposites. Macromolecules 43(16): 6515-6530 (2010)

[23] Bartolucci S F, Paras J, Rafiee M A, Rafiee J, Lee S, Kapoor D, Koratkar N. Graphene-aluminum nanocomposites. Mater Sci Eng: A 528(27): 7933-7937 (2011)

[24] Papageorgiou D G, Kinloch I A, Young R J. Mechanical properties of graphene and graphene-based nanocomposites. Prog Mater Sci 90: 75-127 (2017)

[25] Chieng B W, Ibrahim N A, Yunus W M Z W, Hussein M Z, Giita Silverajah V S. Graphene nanoplatelets as novel reinforcement filler in poly(lactic acid)/epoxidized palm oil green nanocomposites: Mechanical properties. Int $J$ Mol Sci 13(9): 10920-10934 (2012)

[26] El Achaby M, Arrakhiz F E, Vaudreuil S, El Kacem Qaiss A, Bousmina M, Fassi-Fehri O. Mechanical, thermal, and rheological properties of graphene-based polypropylene nanocomposites prepared by melt mixing. Polym Compos 33(5): 733-744 (2012)

[27] Ni Y, Chen L, Teng K, Shi J, Qian X M, Xu Z W, Tian X, $\mathrm{Hu}$ C S, Ma M J. Superior mechanical properties of epoxy composites reinforced by 3D interconnected graphene skeleton. ACS Appl Mater Interfaces 7(21): 11583-11591 (2015)

[28] Lee B, Lee D, Lee J H, Ryu H J, Hong S H. Enhancement of toughness and wear resistance in boron nitride nanoplatelet (BNNP) reinforced $\mathrm{Si}_{3} \mathrm{~N}_{4}$ nanocomposites. Sci Rep 6(1): 27609 (2016)

[29] Porwal H, Saggar R, Tatarko P, Grasso S, Saunders T, Dlouhý I, Reece M J. Effect of lateral size of graphene nano-sheets on the mechanical properties and machinability of alumina nano-composites. Ceram Int 42(6): $7533-$ 7542 (2016)

[30] Lee B, Koo M Y, Jin S H, Kim K T, Hong S H. Simultaneous strengthening and toughening of reduced graphene oxide/alumina composites fabricated by molecular- level mixing process. Carbon 78: 212-219 (2014)

[31] Sun J Y, Chen Y B, Priydarshi M K, Chen Z, Bachmatiuk A, Zou Z Y, Chen Z L, Song X J, Gao Y F, 
Rümmeli M H, et al. Direct chemical vapor depositionderived graphene glasses targeting wide ranged applications. Nano Lett 15(9): 5846-5854 (2015)

[32] Wang X J, Lu M Y, Qiu L, Huang H, Li D, Wang H T, Cheng Y B. Graphene/titanium carbide composites prepared by sol-gel infiltration and spark plasma sintering. Ceram Int 42(1): 122-131 (2016)

[33] Colombo P, Mera G, Riedel R, Sorarù G D. Polymerderived ceramics: 40 years of research and innovation in advanced ceramics. J Am Ceram Soc 93(7): 1805- 1837 (2010)

[34] Xiao Y L, Yao P P, Fan K Y, Zhou H B, Deng M W, Jin $\mathrm{Z}$ X. Powder metallurgy processed metal-matrix friction materials for space applications. Friction 6(2): 219-229 (2018)

[35] Ye H Z, Liu X Y, Hong H P. Fabrication of metal matrix composites by metal injection molding-A review. $J$ Mater Process Technol 200(1-3): 12-24 (2008)

[36] Song Y, He G Y, Wang Y G, Chen Y. Tribological behavior of boron nitride nanoplatelet reinforced $\mathrm{Ni}_{3} \mathrm{Al}$ intermetallic matrix composite fabricated by selective laser melting. Mater Design 165: 107579 (2019)

[37] Hwang J, Yoon T, Jin S H, Lee J, Kim T S, Hong S H, Jeon S. Enhanced mechanical properties of graphene/ copper nanocomposites using a molecular-level mixing process. Adv Mater 25(46): 6724-6729 (2013)

[38] Naseer A, Ahmad F, Aslam M, Guan B H, Harun W S W, Muhamad N, Raza M R, German R M. A review of processing techniques for graphene-reinforced metal matrix composites. Mater Manuf Processes 34(9): 957985 (2019)

[39] Zhang H, Wang L B, Zhou A G, Shen C L, Dai Y H, Liu F F, Chen J F, Li P, Hu Q K. Effects of 2-D transition metal carbide $\mathrm{Ti}_{2} \mathrm{CT}_{x}$ on properties of epoxy composites. RSC Adv 6(90): 87341-87352 (2016)

[40] Sorrentino A, Altavilla C, Merola M, Senatore A, Ciambelli P, Iannace S. Nanosheets of $\mathrm{MoS}_{2}$-oleylamine as hybrid filler for self-lubricating polymer composites: Thermal, tribological, and mechanical properties. Polym Compos 36(6): 1124-1134 (2015)

[41] Xiao Q, Han W H, Yang R, You Y, Wei R B, Liu X B. Mechanical, dielectric, and thermal properties of polyarylene ether nitrile and boron nitride nanosheets composites. Polym Compos 39(S3): E1598-E1605 (2018)

[42] Dai W, Yu J H, Wang Y, Song Y Z, Bai H, Nishimura K, Liao H W, Jiang N. Enhanced thermal and mechanical properties of polyimide/graphene composites. Macromol Res 22(9): 983-989 (2014)

[43] Papageorgiou D G, Liu M F, Li Z L, Vallés C, Young R J, Kinloch I A. Hybrid poly(ether ether ketone) composites reinforced with a combination of carbon fibres and graphene nanoplatelets. Compos Sci Technol 175: 60-
68 (2019)

[44] Cao Z, Wang X D, Li J L, Wu Y, Zhang H P, Guo J Q, Wang $\mathrm{S}$ Q. Reinforcement with graphene nanoflakes in titanium matrix composites. J Alloys Compd 696: 498502 (2017)

[45] Chen F Y, Ying J M, Wang Y F, Du S Y, Liu Z P, Huang Q. Effects of graphene content on the microstructure and properties of copper matrix composites. Carbon 96: 836-842 (2016)

[46] Yan S J, Dai S L, Zhang X Y, Yang C, Hong Q H, Chen J $\mathrm{Z}$, Lin $\mathrm{Z} \mathrm{M}$. Investigating aluminum alloy reinforced by graphene nanoflakes. Mater Sci Eng: A 612: 440-444 (2014)

[47] Tang L C, Wan Y J, Yan D, Pei Y B, Zhao L, Li Y B, Wu L B, Jiang J X, Lai $G$ Q. The effect of graphene dispersion on the mechanical properties of graphene/ epoxy composites. Carbon 60: 16-27 (2013)

[48] Wang Y, Shi Z X, Yin J. Boron nitridenanosheets: Large-scale exfoliation in methanesulfonic acid and their composites with polybenzimidazole. J Mater Chem 21(30): 11371-11377 (2011)

[49] Shao G S, Liu P, Zhang K, Li W, Chen X H, Ma F C. Mechanical properties of graphene nanoplates reinforced copper matrix composites prepared by electrostatic selfassembly and spark plasma sintering. Mater Sci Eng: A 739: 329-334 (2019)

[50] Kumar A, Zo S M, Kim J H, Kim S C, Han S S. Enhanced physical, mechanical, and cytocompatibility behavior of polyelectrolyte complex hydrogels by reinforcing halloysite nanotubes and graphene oxide. Compos Sci Technol 175: 35-45 (2019)

[51] Wang Y, Shi Z X, Fang J H, Xu H J, Ma X D, Yin J. Direct exfoliation of graphene in methanesulfonic acid and facile synthesis of graphene/polybenzimidazole nanocomposites. J Mater Chem 21(2): 505-512 (2011)

[52] Feng X M, Wang X, Xing W Y, Zhou K Q, Song L, Hu Y. Liquid-exfoliated $\mathrm{MoS}_{2}$ by chitosan and enhanced mechanical and thermal properties of chitosan/ $\mathrm{MoS}_{2}$ composites. Compos Sci Technol 93: 76-82 (2014)

[53] Tandon G P, Weng G J. The effect of aspect ratio of inclusions on the elastic properties of unidirectionally aligned composites. Polym Compos 5(4): 327-333 (1984)

[54] Affdl J C H, Kardos J. The Halpin-Tsai equations: A review. Polym Eng Sci 16(5): 344-352 (1976)

[55] Zhao X, Zhang Q H, Chen D J, Lu P. Enhanced mechanical properties of graphene-based Poly(vinyl alcohol) composites. Macromolecules 43(5): 2357- 2363 (2010)

[56] Sandhya P K, Sreekala M S, Padmanabhan M, Jesitha K, Thomas S. Effect of starch reduced graphene oxide on thermal and mechanical properties of phenol formaldehyde resin nanocomposites. Compos Part B: Eng 167: 83-92 (2019) 
[57] Spanos K N, Anifantis N K. Mechanical characterization of hexagonal boron nitride nanocomposites: A multiscale finite element prediction. J Compos Mater 52(16): 22292241 (2017)

[58] Guo Z X, Song L B, Chai G B, Li Z G, Li Y C, Wang Z H. Multiscale finite element analyses on mechanical properties of graphene-reinforced composites. Mech $A d v$ Mater Struc 26(20): 1735-1742 (2018)

[59] Verma A, Parashar A, Packirisamy M. Effect of grain boundaries on the interfacial behaviour of graphenepolyethylene nanocomposite. Appl Surf Sci 470: 10851092 (2019)

[60] Zhan J M, Yao X H, Li W H, Zhang X Q. Tensile mechanical properties study of $\mathrm{SiC} /$ graphene composites based on molecular dynamics. Comp Mater Sci 131: 266-274 (2017)

[61] Klimek-McDonald D R, King J A, Miskioglu I, Pineda E J, Odegard G M. Determination and modeling of mechanical properties for graphene nanoplatelet/ epoxy composites. Polym Compos 39(6): 1845-1851 (2018)

[62] Shiu S C, Tsai J L. Characterizing thermal and mechanical properties of graphene/epoxy nanocomposites. Compos Part B: Eng 56: 691-697 (2014)

[63] Dai G M, Mishnaevsky Jr L. Graphene reinforced nanocomposites: 3D simulation of damage and fracture. Comp Mater Sci 95: 684-692 (2014)

[64] Lee S, Hong J Y, Jang J. The effect of graphene nanofiller on the crystallization behavior and mechanical properties of poly(vinyl alcohol). Polym Int 62(6): 901-908 (2013)

[65] Das B, Eswar Prasad K, Ramamurty U, Rao C N R. Nano-indentation studies on polymer matrix composites reinforced by few-layer graphene. Nanotechnology 20(12): 125705 (2009)

[66] Du B Y, Tsui O K C, Zhang Q L, He T B. Study of elastic modulus and yield strength of polymer thin films using atomic force microscopy. Langmuir 17(11): 32863291 (2001)

[67] Yan Z, Shi X L, Huang Y C, Deng X B, Liu X Y, Yang K. Tribological performance of $\mathrm{Ni}_{3} \mathrm{Al}$ matrix self- lubricating composites containing multilayer graphene prepared by additive manufacturing. J Mater Eng Perform 27(1): 167-175 (2018)

[68] Zhang L G, Qi H M, Li G T, Wang D A, Wang T M, Wang Q H, Zhang G. Significantly enhanced wear resistance of PEEK by simply filling with modified graphitic carbon nitride. Mater Design 129: 192-200 (2017)

[69] Salvetat-Delmotte J P, Rubio A. Mechanical properties of carbon nanotubes: A fiber digest for beginners. Carbon 40(10): 1729-1734 (2002)

[70] Ashby M F. Overview No. 80: On the engineering properties of materials. Acta Metall 37(5): 1273-1293 (1989)
[71] Zhang L B, Wang JQ, Wang HG, Xu Y, Wang Z F, Li Z P, Mi Y J, Yang S R. Preparation, mechanical and thermal properties of functionalized graphene/polyimide nanocomposites. Compos Part A: Appl Sci Manuf 43(9): 1537-1545 (2012)

[72] Vadukumpully S, Paul J, Mahanta N, Valiyaveettil S. Flexible conductive graphene/poly(vinyl chloride) composite thin films with high mechanical strength and thermal stability. Carbon 49(1): 198-205 (2011)

[73] Wang X, Xing W Y, Feng X M, Yu B, Song L, Yeoh G H, $\mathrm{Hu}$ Y. Enhanced mechanical and barrier properties of polyurethane nanocomposite films with randomly distributed molybdenum disulfide nanosheets. Compos Sci Technol 127: 142-148 (2016)

[74] Suh J, Bae D. Mechanical properties of polytetrafluoroethylene composites reinforced with graphene nanoplatelets by solid-state processing. Compos Part B: Eng 95: 317-323 (2016)

[75] Wang W L, Sun G X, Chen Y F, Sun X M, Bi J Q. Preparation and mechanical properties of boron nitride nanosheets/alumina composites. Ceram Int 44(17): 21993-21997 (2018)

[76] Jiang L Q, Xie H A, Hou Y, Wang S, Xia Y S, Li Y, Hu G H, Yang Q L, Xiong C X, Gao Z D F. Enhanced piezoelectricity of a PVDF-based nanocomposite utilizing high-yield dispersions of exfoliated few-layer $\mathrm{MoS}_{2}$. Ceram Int 45(9): 11347-11352 (2019)

[77] Zhang D D, Zhan Z J. Preparation of graphene nanoplatelets-copper composites by a modified semipowder method and their mechanical properties. $J$ Alloys Compd 658: 663-671 (2016)

[78] Duan Z Q, Liu Y T, Xie X M, Ye X Y. A simple and green route to transparent boron nitride/PVA nanocomposites with significantly improved mechanical and thermal properties. Chin Chem Lett 24(1): 17-19 (2013)

[79] Kiran M S R N, Raidongia K, Ramamurty U, Rao C N R. Improved mechanical properties of polymer nanocomposites incorporating graphene-like BN: Dependence on the number of BN layers. Scripta Mater 64(6): 592-595 (2011)

[80] Krystek M, Pakulski D, Patroniak V, Górski M, Szojda L, Ciesielski A, Samorì P. High-performance graphenebased cementitious composites. Adv Sci 6(9): 1801195 (2019)

[81] Asgharzadeh H, Sedigh M. Synthesis and mechanical properties of Al matrix composites reinforced with few-layer graphene and graphene oxide. J Alloys Compd 728: 47-62 (2017)

[82] Saggar R, Porwal H, Tatarko P, Dlouhý I, Reece M J. Boron nitride nanosheets reinforced glass matrix composites. Adv Appl Ceram 114(S1): S26-S33 (2015)

[83] Khan U, May P, O'Neill A, Bell A P, Boussac E, Martin 
A, Semple J, Coleman J N. Polymer reinforcement using liquid-exfoliated boron nitride nanosheets. Nanoscale 5(2): 581-587 (2013)

[84] Zhou K Q, Jiang S H, Bao C L, Song L, Wang B B, Tang $\mathrm{G}, \mathrm{Hu} \mathrm{Y}$, Gui Z. Preparation of poly(vinyl alcohol) nanocomposites with molybdenum disulfide $\left(\mathrm{MoS}_{2}\right)$ : Structural characteristics and markedly enhanced properties. RSC Adv 2(31): 11695-11703 (2012)

[85] Jiang S D, Tang G, Bai Z M, Wang Y Y, Hu Y, Song L. Surface functionalization of $\mathrm{MoS}_{2}$ with POSS for enhancing thermal, flame-retardant and mechanical properties in PVA composites. RSC Adv 4(7): 3253- 3262 (2014)

[86] Liu L, Shen Z G, Zheng Y T, Yi M, Zhang X J, Ma S L. Boron nitride nanosheets with controlled size and thickness for enhancing mechanical properties and atomic oxygen erosion resistance. $R S C A d v$ 4(71): 37726-37732 (2014)

[87] Meng W J, Huang Y, Fu Y Q, Wang Z F, Zhi C Y. Polymer composites of boron nitride nanotubes and nanosheets. J Mater Chem C 2(47): 10049-10061 (2014)

[88] Cui Z H, Martinez A P, Adamson D H. PMMA functionalized boron nitride sheets as nanofillers. Nanoscale 7(22): 10193-10197 (2015)

[89] Zhang D D, Zhan Z J. Experimental investigation of interfaces in graphene materials/copper composites from a new perspective. $R S C A d v$ 6(57): 52219-52226 (2016)

[90] Kwon O S, Lee D, Lee S P, Kang Y G, Kim N C, Song S $H$. Enhancing the mechanical and thermal properties of boron nitride nanoplatelets/elastomer nanocomposites by latex mixing. $R S C A d v$ 6(65): 59970-59975 (2016)

[91] Zhao C. Enhanced strength in reduced graphene oxide/nickel composites prepared by molecular-level mixing for structural applications. Appl Phys A 118(2): 409-416 (2015)

[92] Zhang H P, Xu C, Xiao W L, Ameyama K, Ma C L. Enhanced mechanical properties of A15083 alloy with graphene nanoplates prepared by ball milling and hot extrusion. Mater Sci Eng: A 658: 8-15 (2016)

[93] Yu Z H, Yang W S, Zhou C, Zhang N B, Chao Z L, Liu H, Cao Y F, Sun Y, Shao P Z, Wu G H. Effect of ball milling time on graphene nanosheets reinforced A16063 composite fabricated by pressure infiltration method. Carbon 141: 25-39 (2019)

[94] Xia H Y, Zhang X, Shi Z Q, Zhao C J, Li Y F, Wang J P, Qiao G J. Mechanical and thermal properties of reduced graphene oxide reinforced aluminum nitride ceramic composites. Mater Sci Eng: A 639: 29-36 (2015)

[95] Wu J K, Ye C C, Liu T, An Q F, Song Y H, Lee K R, Hung W S, Gao C J. Synergistic effects of CNT and GO on enhancing mechanical properties and separation performance of polyelectrolyte complex membranes. Mater Design 119: 38-46 (2017)

[96] Wang F Z, Drzal L T, Qin Y, Huang Z X. Mechanical properties and thermal conductivity of graphene nanoplatelet/epoxy composites. J Mater Sci 50(3): 1082 1093 (2015)

[97] Wang X, Yang H Y, Song L, Hu Y, Xing W Y, Lu H D. Morphology, mechanical and thermal properties of graphene-reinforced poly(butylene succinate) nanocomposites. Compos Sci Technol 72(1): 1-6 (2011)

[98] Wan Y J, Gong L X, Tang L C, Wu L B, Jiang J X. Mechanical properties of epoxy composites filled with silane-functionalized graphene oxide. Compos Part A: Appl Sci Manuf 64: 79-89 (2014)

[99] Tang Y X, Yang X M, Wang R R, Li M X. Enhancement of the mechanical properties of graphene-copper composites with graphene-nickel hybrids. Mater Sci Eng: A 599: 247-254 (2014)

[100] Lee D, Song S H, Hwang J, Jin S H, Park K H, Kim B $\mathrm{H}$, Hong S H, Jeon S. Enhanced mechanical properties of epoxy nanocomposites by mixing noncovalently functionalized boron nitride nanoflakes. Small 9(15): 2602-2610 (2013)

[101] Zhao X L, Qi S H, Liu J J, Han X, Zhang F. Preparation and mechanical performances of carbon fiber reinforced epoxy composites by Mxene nanosheets coating. $J$ Mater Sci: Mater Electron 30(11): 10516-10523 (2019)

[102] Surudžić R, Janković A, Bibić N, Vukašinović-Sekulić M, Perić-Grujić A, Mišković-Stanković V, Park S J, Rhee K Y. Physico-chemical and mechanical properties and antibacterial activity of silver/poly(vinyl alcohol)/ graphene nanocomposites obtained by electrochemical method. Compos Part B: Eng 85: 102-112 (2016)

[103] Rodenas T, Luz I, Prieto G, Seoane B, Miro H, Corma A, Kapteijn F, Llabrés I X F X, Gascon J. Metalorganic framework nanosheets in polymer composite materials for gas separation. Nat Mater 14(1): 48-55 (2015)

[104] Al-Saleh M H, Sundararaj U. Review of the mechanical properties of carbon nanofiber/polymer composites. Compos Part A: Appl Sci Manuf 42(12): 2126-2142 (2011)

[105] Elanchezhian C, Ramnath B V, Ramakrishnan G, Rajendrakumar M, Naveenkumar V, Saravanakumar M $\mathrm{K}$. Review on mechanical properties of natural fiber composites. Mater Today: Proc 5(1): 1785-1790 (2018)

[106] Frogley M D, Ravich D, Wagner H D. Mechanical properties of carbon nanoparticle-reinforced elastomers. Compos Sci Technol 63(11): 1647-1654 (2003)

[107] Balazs A C, Emrick T, Russell T P. Nanoparticle polymer composites: Where two small worlds meet. Science 314(5802): 1107-1110 (2006)

[108] Zhang L, Xie G X, Wu S, Peng S G, Zhang X Q, Guo D, Wen S Z, Luo J B. Ultralow friction polymer composites 
incorporated with monodispersed oil microcapsules. Friction, in press, DOI 10.1007/s40544- 019-0312-4.

[109] Zhao Y, Liu B, You C, Chen M F. Effects of MgO whiskers on mechanical properties and crystallization behavior of PLLA/MgO composites. Mater Design 89: 573-581 (2016)

[110] Wang X C, Song R F, Chen Y J, Zhao Y H, Zhu K Y, Yuan X Y. Mechanical properties of polypropylene by diversely compatibilizing with titanate whiskers in composites. Compos Sci Technol 164: 103-109 (2018)

[111] Verdejo R, Bernal M M, Romasanta L J, LopezManchado M A. Graphene filled polymer nanocomposites. J Mater Chem 21(10): 3301-3310 (2011)

[112] Ahmad M W, Dey B, Sarkhel G, Bag D S, Choudhury A. Exfoliated graphene reinforced polybenzimidazole nanocomposite with improved electrical, mechanical and thermal properties. Mater Chem Phys 223: 426-433 (2019)

[113] Zhang L Y, Tu S H, Wang H T, Du Q G. Preparation of polymer/graphene oxide nanocomposites by a twostep strategy composed of in situ polymerization and melt processing. Compos Sci Technol 154: 1-7 (2018)

[114] Song M T, Yang J, Kitipornchai S. Bending and buckling analyses of functionally graded polymer composite plates reinforced with graphene nanoplatelets. Compos Part B: Eng 134: 106-113 (2018)

[115] Ren Y J, Zhang Y F, Fang H M, Ding T P, Li J L, Bai S L. Simultaneous enhancement on thermal and mechanical properties of polypropylene composites filled with graphite platelets and graphene sheets. Compos Part A: Appl Sci Manuf 112: 57-63 (2018)

[116] Zhang X D, Xu J G, Wang H, Zhang J J, Yan H B, Pan B C, Zhou J F, Xie Y. Ultrathin nanosheets of MAX phases with enhanced thermal and mechanical properties in polymeric compositions: $\mathrm{Ti}_{3} \mathrm{Si}_{0.75} \mathrm{Al}_{0.25} \mathrm{C}_{2}$. Angew Chem Int Ed Engl 52(16): 4361-4365 (2013)

[117] Rafiee M A, Rafiee J, Wang Z, Song H H, Yu Z Z, Koratkar N. Enhanced mechanical properties of nanocomposites at low graphene content. ACS Nano 3(12): 3884-3890 (2009)

[118] Bora C, Gogoi P, Baglari S, Dolui S K. Preparation of polyester resin/graphene oxide nanocomposite with improved mechanical strength. J Appl Polym Sci 129(6): 3432-3438 (2013)

[119] Cai D Y, Jin J, Yusoh K, Rafiq R, Song M. High performance polyurethane/functionalized graphene nanocomposites with improved mechanical and thermal properties. Compos Sci Technol 72(6): $702-707$ (2012)

[120] Liu Y, Wu H, Chen G H. Enhanced mechanical properties of nanocomposites at low graphene content based on in situ ball milling. Polym Compos 37(4): 1190-1197 (2016)
[121] Liu C Z, Ye S B, Feng J C. Promoting the dispersion of graphene and crystallization of poly (lactic acid) with a freezing-dried graphene/PEG masterbatch. Compos Sci Technol 144: 215-222 (2017)

[122] Hatter C B, Shah J, Anasori B, Gogosi Y. Micromechanical response of two-dimensional transition metal carbonitride (MXene) reinforced epoxy composites. Compos Part B: Eng 182: 107603 (2020)

[123] Jiang L, Shen X P, Wu J L, Shen K C. Preparation and characterization of graphene/poly(vinyl alcohol) nanocomposites. J Appl Polym Sci 118(1): 275-279 (2010)

[124] Sobolčiak P, Ali A, Hassan M K, Helal M I, Tanvir A, Popelka A, Al-Maadeed M A, Krupa K I, Mahmoud K A. 2D $\mathrm{Ti}_{3} \mathrm{C}_{2} \mathrm{~T}_{x}$ (MXene)-reinforced polyvinyl alcohol (PVA) nanofibers with enhanced mechanical and electrical properties. PLoS One 12(8): e0183705 (2017)

[125] Mirkhani S A, Shayesteh Zeraati A, Aliabadian E, Naguib M, Sundararaj U. High dielectric constant and low dielectric loss via Poly(vinyl alcohol) $/ \mathrm{Ti}_{3} \mathrm{C}_{2} \mathrm{~T}_{x}$ MXene nanocomposites. ACS Appl Mater Interfaces 11(20): 18599-18608 (2019)

[126] Young R J, Liu M F, Kinloch I A, Li S H, Zhao X, Vallés C, Papageorgiou D G. The mechanics of reinforcement of polymers by graphene nanoplatelets. Compos Sci Technol 154: 110-116 (2018)

[127] May P, Khan U, O'Neill A, Coleman J N. Approaching the theoretical limit for reinforcing polymers with graphene. J Mater Chem 22(4): 1278-1282 (2012)

[128] Peng Q, Ji W, De S. Mechanical properties of the hexagonal boron nitride monolayer: Ab initio study. Comp Mater Sci 56: 11-17 (2012)

[129] Wu S, He F, Xie G X, Bian Z L, Ren Y L, Liu X Y, Yang H J, Guo D, Zhang L, Wen S Z, Luo J B, Superslippery degraded black phosphorus/silicon dioxide interface. ACS Appl Mater Inter 12(6): 7717-7726 (2020)

[130] Li J, Yin Y H, Muhammad Y, Yang J, Yang S, Yang H Q, Sahibzada M. Preparation and properties of modified graphene oxide incorporated waterborne polyurethane acrylate. Polym Int 68(6): 1091-1101 (2019)

[131] Fang M, Wang K G, Lu H B, Yang Y L, Nutt S. Covalent polymer functionalization of graphenenanosheets and mechanical properties of composites. J Mater Chem 19(38): 7098-7105 (2009)

[132] Zhang L, Li Y F, Wang H H, Qiao Y D, Chen J Z, Cao S K. Strong and ductile poly(lactic acid) nanocomposite films reinforced with alkylated graphene nanosheets. Chem Eng J 264: 538-546 (2015)

[133] Liao W H, Yang S Y, Hsiao S T, Wang Y S, Li S M, Ma C C M, Tien H W, Zeng S J. Effect of octa(aminophenyl) polyhedral oligomeric silsesquioxane functionalized 
graphene oxide on the mechanical and dielectric properties of polyimide composites. ACS Appl Mater Interfaces 6(18): 15802-15812 (2014)

[134] Ye X Y, Gong P W, Wang J Q, Wang H G, Ren S L, Yang S R. Fluorinated graphene reinforced polyimide films with the improved thermal and mechanical properties. Compos Part A: Appl Sci Manuf 75: 96103 (2015)

[135] Chen Y M, Gao X, Wang J L, He W, Silberschmidt V V, Wang S X, Tao Z H, Xu H. Properties and application of polyimide-based composites by blending surface functionalized boron nitride nanoplates. J Appl Polym Sci 132(16): 41889 (2015)

[136] Dong J, Yin C Q, Zhao X, Li Y Z, Zhang Q H. High strength polyimide fibers with functionalized graphene. Polymer 54(23): 6415-6424 (2013)

[137] Qiu F, Hao Y B, Li X Y, Wang B, Wang M. Functionalized graphene sheets filled isotactic polypropylene nanocomposites. Compos Part B: Eng 71: 175-183 (2015)

[138] Xing L X, Li Q, Zhang G Z, Zhang X S, Liu F H, Liu L, Huang Y D, Wang Q. Self-healable polymer nanocomposites capable of simultaneously recovering multiple functionalities. Adv Funct Mater 26(20): 3524-3531 (2016)

[139] Chen M T, Tao T, Zhang L, Gao W, Li C Z. Highly conductive and stretchable polymer composites based on graphene/MWCNT network. Chem Commun 49(16): 1612-1614 (2013)

[140] Li Z L, Chu J W, Yang C, Hao S J, Bissett M A, Kinloch I A, Young R J. Effect of functional groups on the agglomeration of graphene in nanocomposites. Compos Sci Technol 163: 116-122 (2018)

[141] Damnal1, O F, Eskizeybek V. Synergistic impact of graphene and carbon nanotubes on waste paper for hybrid nanocomposite substrates. Cellulose 26(6): 3935-3954 (2019)

[142] Mohan V B, Brown R, Jayaraman K, Bhattacharyya D. Optimisation of hybridisation effect in graphene reinforced polymer nanocomposites. Adv Compos Mater 27(4): 349-365 (2018)

[143] Cui X L, Ding P, Zhuang N, Shi L Y, Song N, Tang S F. Thermal conductive and mechanical properties of polymeric composites based on solution-exfoliated boron nitride and graphene nanosheets: A morphologypromoted synergistic effect. ACS Appl Mater Interfaces 7(34): 19068-19075 (2015)

[144] Wu S, He F, Xie G X, Bian Z L, Luo J B, Wen S Z. Black phosphorus: Degradation favors lubrication. Nano Lett 18(9): 5618-5627 (2018)

[145] Zhang Z Z, Yang M M, Yuan J Y, Guo F, Men X H. Friction and wear behaviors of $\mathrm{MoS}_{2}$-multi-walled- carbonnanotube hybrid reinforced polyurethane composite coating. Friction 7(4): 316-326 (2019)

[146] Zhang G L, Xie G X, Si L N, Wen S Z, Guo D. Ultralow friction self-lubricating nanocomposites with mesoporous metal-organic frameworks as smart nanocontainers for lubricants. ACS Appl Mater Interfaces 9(43): 38146 38152 (2017)

[147] Peng S G, Guo Y, Xie G X, Luo J B. Tribological behavior of polytetrafluoroethylene coating reinforced with black phosphorus nanoparticles. Appl Surf Sci 441: 670-677 (2018)

[148] Bhargava S, Koratkar N, Blanchet T A. Effect of platelet thickness on wear of graphene-polytetrafluoroethylene (PTFE) composites. Tribol Lett 59(1): 17 (2015)

[149] Li S, Duan C J, Li X, Shao M C, Qu C H, Zhang D, Wang Q H, Wang T M, Zhang X R. The effect of different layered materials on the tribological properties of PTFE composites. Friction 8(3): 542-552 (2020)

[150] Lv Y, Wang W, Xie G X, Luo J B. Self-lubricating PTFE-based composites with black phosphorus nanosheets. Tribol Lett 66(2): 61 (2018)

[151] Chen J, Chen B, Li J Y, Tong X, Zhao H C, Wang L P. Enhancement of mechanical and wear resistance performance in hexagonal boron nitride-reinforced epoxy nanocomposites. Polym Int 66(5): 659-664 (2017)

[152] Min Y J, Kang K H, Kim D E. Development of polyimide films reinforced with boron nitride and boron nitride nanosheets for transparent flexible device applications. Nano Res 11(5): 2366-2378 (2018)

[153] Yang M M, Zhang Z Z, Zhu X T, Men X H, Ren G N. In situ reduction and functionalization of graphene oxide to improve the tribological behavior of a phenol formaldehyde composite coating. Friction 3(1): 72-81 (2015)

[154] Qiu S L, Hu Y X, Shi Y Q, Hou Y B, Kan Y C, Chu F K, Sheng H B, Yuen R K K, Xing W Y. In situ growth of polyphosphazene particles on molybdenum disulfide nanosheets for flame retardant and friction application. Compos Part A: Appl Sci Manuf 114: 407-417 (2018)

[155] Chen Z Y, Yan H X, Guo L L, Li L, Yang P F, Liu B. A novel polyamide-type cyclophosphazene functionalized $\mathrm{rGO} / \mathrm{WS}_{2}$ nanosheets for bismaleimide resin with enhanced mechanical and tribological properties. Compos Part A: Appl Sci Manuf 121: 18-27 (2019)

[156] Zhang H, Wang L B, Chen Q, Li P, Zhou A G, Cao X X, $\mathrm{Hu} \mathrm{Q}$ K. Preparation, mechanical and anti-friction performance of MXene/polymer composites. Mater Design 92: 682-689 (2016)

[157] Kandanur S S, Rafiee M A, Yavari F, Schrameyer M, 
Yu Z Z, Blanchet T A, Koratkar N. Suppression of wear in graphene polymer composites. Carbon 50(9): $3178-3183$ (2012)

[158] Lahiri D, Hec F, Thiesse M, Durygin A, Zhang C, Agarwal A. Nanotribological behavior of graphene nanoplatelet reinforced ultra high molecular weight polyethylene composites. Tribol Int 70: 165-169 (2014)

[159] Zhao J, Chen G Y, He Y Y, Li S X, Duan Z Q, Li Y R, Luo J B. A novel route to the synthesis of an $\mathrm{Fe}_{3} \mathrm{O}_{4} /$ h-BN 2D nanocomposite as a lubricant additive. $R S C$ $A d v$ 9(12): 6583-6588 (2019)

[160] Xu Z, Lou W J, Zhao G Q, Zhao Q, Xu N, Hao J Y, Wang X B. Preparation of $\mathrm{WS}_{2}$ nanocomposites via mussel-inspired chemistry and their enhanced dispersion stability and tribological performance in polyalkylene glycol. J Dispersion Sci Technol 40(5): 737-744 (2019)

[161] Chen F, Jin D Q, Tyeb K, Wang B T, Han Y H, Kim S, Schoenung J M, Shen Q, Zhang L M. Field assisted sintering of graphene reinforced zirconia ceramics. Ceram Int 41(4): 6113-6116 (2015)

[162] Fan Y C, Igarashi G, Jiang W, Wang L J, Kawasaki A. Highly strain tolerant and tough ceramic composite by incorporation of graphene. Carbon 90: 274-283 (2015)

[163] Liu X, Fan Y C, Li J L, Wang L J, Jiang W. Preparation and mechanical properties of graphene nanosheet reinforced alumina composites. Adv Eng Mater 17(1): 28-35 (2015)

[164] Pan Z, He L, Qiu L, Korayem A H, Li G, Zhu J W, Collins F, Li D, Duan W H, Wang M C. Mechanical properties and microstructure of a graphene oxidecement composite. Cem Concr Compos 58: 140-147 (2015)

[165] Rutkowski P, Stobierski L, Zientara D, Jaworska L, Klimczyk P, Urbanik M. The influence of the graphene additive on mechanical properties and wear of hotpressed $\mathrm{Si}_{3} \mathrm{~N}_{4}$ matrix composites. J Eur Ceram Soc 35(1): 87-94 (2015)

[166] Yun C, Feng Y B, Qiu T, Yang J, Li X Y, Yu L. Mechanical, electrical, and thermal properties of graphene nanosheet/aluminum nitride composites. Ceram Int 41(7): 8643-8649 (2015)

[167] Han X P, Huang Y, Zhou S H, Sun X, Peng X Y, Chen $X$ F. Effects of graphene content on thermal and mechanical properties of chromium-coated graphite flakes/Si/Al composites. J Mater Sci: Mater Electron 29(5): 4179- 4189 (2018)

[168] Cano-Crespo R, Moshtaghioun B M, Gómez-García D, Moreno R, Domínguez-Rodríguez A. Graphene or carbon nanofiber-reinforced zirconia composites: Are they really worthwhile for structural applications? $J$
Eur Ceram Soc 38(11): 3994-4002 (2018)

[169] Yin Z B, Yuan J T, Xu W W, Liu K, Yan S Y. Graphene nanosheets toughened $\mathrm{TiB}_{2}$-based ceramic tool material by spark plasma sintering. Ceram Int 44(8): $8977-$ 8982 (2018)

[170] An Y M, Xu X H, Gui K X. Effect of SiC whiskers and graphene nanosheets on the mechanical properties of $\mathrm{ZrB}_{2}-\mathrm{SiC}_{\mathrm{w}}$-Graphene ceramic composites. Ceram Int 42(12): 14066-14070 (2016)

[171] Markandan K, Chin J K, Tan M T T. Recent progress in graphene based ceramic composites: A review. $J$ Mater Res 32(1): 84-106 (2017)

[172] Nieto A, Bisht A, Lahiri D, Zhang C, Agarwal A. Graphene reinforced metal and ceramic matrix composites: A review. Int Mater Rev 62(5): 241-302 (2017)

[173]Birenboim M, Nadiv R, Alatawna A, Buzaglo M, Schahar G, Lee J, et al. Reinforcement and workability aspects of graphene-oxide-reinforced cement nanocomposites. Compos Part B: Eng 161: 68-76 (2019)

[174] Li Y J, Ge B Z, Wu Z H, Xiao G Q, Shi Z Q, Jin Z H. Effects of h-BN on mechanical properties of reaction bonded $\beta$-SiAlON/h-BN composites. J Alloys Compd 703: 180-187 (2017)

[175] Li Q, Cai D L, Yang Z H, Duan X M, Li D X, Sun Y S, Wang S J, Jia D C, Joachim B, Zhou Y. Effects of BN on the microstructural evolution and mechanical properties of BAS-BN composites. Ceram Int 45(2): 1627-1633 (2019)

[176] Fei M M, Lin R Z, Lu Y W, Zhang X L, Bian R J, Cheng J G, Luo P F, Xu C X, Cai D Y. MXenereinforced alumina ceramic composites. Ceram Int 43(18): 17206-17210 (2017)

[177] Guo J, Legum B, Anasori B, Wang K, Lelyukh P, Gogotsi Y, Randall C A. Cold sintered ceramic nanocomposites of 2D MXene and zinc oxide. $A d v$ Mater 30(32): 1801846 (2018)

[178] Belmonte M, Ramírez C, González-Julián J, Schneider J, Miranzo P, Osendi M I. The beneficial effect of graphene nanofillers on the tribological performance of ceramics. Carbon 61: 431-435 (2013)

[179] Porwal H, Tatarko P, Saggar R, Grasso S, Kumar Mani M, Dlouhý I, Dusza J, Reece M J. Tribological properties of silica-graphene nano-platelet composites. Ceram Int 40(8): 12067-12074 (2014)

[180] Zeng Z Y B, Liu Y Z, Guo R R, Li K L. Friction and wear behaviours of in situ reduced graphene oxide reinforced zirconia ceramic. Int J Refract Met Hard Mater 79: 164-170 (2019)

[181] Llorente J, Ramírez C, Belmonte M. High graphene fillers content for improving the tribological performance of silicon nitride-based ceramics. Wear 430-431: 183-190 (2019) 
[182] Su Y F, Zhang Y S, Song J J, Hu L T. Novel approach to the fabrication of an alumina- $\mathrm{MoS}_{2}$ self-lubricating composite via the in situ synthesis of nanosized $\mathrm{MoS}_{2}$. ACS Appl Mater Interfaces 9(36): 30263-30266 (2017)

[183] Serra E C, Soares V F D, Fernandez D A R, Hübler R, Juste K R C, Lima C L, Tentardini E K. Influence of $\mathrm{WS}_{2}$ content on high temperature wear performance of magnetron sputtered TiN-WS $\mathrm{W}_{x}$ thin films. Ceram Int 45(16): 19918-19924 (2019)

[184] Zhang W L, Schröder C, Schlüter B, Knoch M, Dusza J, Sedlák R, Mülhaupt R, Kailer A. Effect of mechanochemically functionalized multilayer graphene on the tribological properties of silicon carbide/ graphene nanocomposites in aqueous environment. Tribol Lett 66(4): 121 (2018)

[185] Kim H J, Lee S M, Oh Y S, Yang Y H, Lim Y S, Yoon D H, Lee C, Kim J Y, Ruoff R S. Unoxidized graphene/alumina nanocomposite: Fracture-and wearresistance effects of graphene on alumina matrix. Sci Rep 4(1): 5176 (2015)

[186] Llorente J, Belmonte M. Friction and wear behaviour of silicon carbide/graphene composites under isooctane lubrication. J Eur Ceram Soc 38(10): 3441-3446 (2018)

[187] Dutkiewicz J, Ozga P, Maziarz W, Pstruś J, Kania B, Bobrowski P, Stolarska J. Microstructure and properties of bulk copper matrix composites strengthened with various kinds of graphene nanoplatelets. Mater Sci Eng: A 628: 124-134 (2015)

[188] Li M X, Xie J, Li Y D, Xu H H. Reduced graphene oxide dispersed in copper matrix composites: Facile preparation and enhanced mechanical properties. Phys Status Solidi A 212(10): 2154-2161 (2015)

[189] Gao X, Yue H Y, Guo E J, Zhang H, Lin X Y, Yao L H, Wang B. Mechanical properties and thermal conductivity of graphene reinforced copper matrix composites. Powder Technol 301: 601-607 (2016)

[190] Chen Y K, Zhang X, Liu E Z, He C N, Shi C S, Li J J, Nash P, Zhao N Q. Fabrication of in-situ grown graphene reinforced $\mathrm{Cu}$ matrix composites. Sci Rep 6(1): 19363 (2016)

[191] Wang L D, Yang Z Y, Cui Y, Wei B, Xu S C, Sheng J, Wang M, Zhu Y P, Fei W D. Graphene-copper composite with micro-layered grains and ultrahigh strength. Sci Rep 7(1): 41896 (2017)

[192] Rashad M, Pan F S, Yu Z W, Asif M, Lin H, Pan R J. Investigation on microstructural, mechanical and electrochemical properties of aluminum composites reinforced with graphene nanoplatelets. Prog Nat Sci: Mater 25(5): 460-470 (2015)

[193] Li Z, Guo Q, Li Z Q, Fan G L, Xiong D B, Su Y S, Zhang J, Zhang D. Enhanced mechanical properties of graphene (reduced graphene oxide)/aluminum composites with a bioinspired nanolaminated structure. Nano Lett 15(12): 8077-8083 (2015)

[194] Dasari B L, Morshed M, Nouri J M, Brabazon D, Naher S. Mechanical properties of graphene oxide reinforced aluminium matrix composites. Compos Part B: Eng 145: 136-144 (2018)

[195] Rashad M, Pan F S, Tang A T, Asif M, She J, Gou J, Mao J J, Hu H H. Development of magnesiumgraphene nanoplatelets composite. J Compos Mater 49(3): 285-293 (2015)

[196] Ren Z D, Meng N, Shehzad K, Xu Y, Qu S X, Yu B, Luo J K. Mechanical properties of nickel-graphene composites synthesized by electrochemical deposition. Nanotechnology 26(6): 065706 (2015)

[197] Xu Z S, Shi X L, Zhai W Z, Yao J, Song S Y, Zhang Q $X$. Preparation and tribological properties of $\mathrm{TiAl}$ matrix composites reinforced by multilayer graphene. Carbon 67: 168-177 (2014)

[198] Hidalgo-Manrique P, Lei X Z, Xu R Y, Zhou M Y, Kinloch I A, Young R J. Copper/graphene composites: A review. J Mater Sci 54(19): 12236-12289 (2019)

[199] Mohan V B, Lau K T, Hui D, Bhattacharyya D. Graphene-based materials and their composites: A review on production, applications and product limitations. Compos Part B: Eng 142: 200-220 (2018)

[200] Hu Z, Tong G, Lin D, Chen C, Guo H, Xu J, Zhou L. Graphene-reinforced metal matrix nanocompositesA review. Mater Sci Technol 32(9): 930-953 (2016)

[201] Wu L Q, Wu R Z, Hou L G, Zhang J H, Zhang M L. Microstructure, mechanical properties and wear performance of AZ31 matrix composites reinforced by graphene nanoplatelets(GNPs). J Alloys Compd 750: 530-536 (2018)

[202] Dorri Moghadam A, Omrani E, Menezes P L, Rohatgi $P$ K. Mechanical and tribological properties of selflubricating metal matrix nanocomposites reinforced by carbon nanotubes (CNTs) and graphene-A review. Compos Part B: Eng 77: 402-420 (2015)

[203] Rashad M, Pan F S, Hu H H, Asif M, Hussain S, She J. Enhanced tensile properties of magnesium composites reinforced with graphene nanoplatelets. Mater Sci Eng: A 630: 36-44 (2015)

[204] Xiong D B, Cao M, Guo Q, Tan Z Q, Fan G L, Li Z Q, Zhang D. Graphene-and-copper artificial nacre fabricated by a preform impregnation process: Bioinspired strategy for strengthening-toughening of metal matrix composite. ACS Nano 9(7): 6934-6943 (2015)

[205] Song Y, Chen Y, Liu W W, Li W L, Wang Y G, Zhao D, Liu $X$ B. Microscopic mechanical properties of titanium composites containing multi-layer graphene nanofillers. Mater Design 109: 256-263 (2016)

[206] Zhang D D, Zhan Z J. Strengthening effect of 
graphene derivatives in copper matrix composites. $J$ Alloys Compd 654: 226-233 (2016)

[207] Kumar S. Graphene engendered aluminium crystal growth and mechanical properties of its composite: An atomistic investigation. Mater Chem Phys 208: 41-48 (2018)

[208] Wan Y Z, Wang Y L, Luo H L, Dong X H, Cheng G X. Effects of fiber volume fraction, hot pressing parameters and alloying elements on tensile strength of carbon fiber reinforced copper matrix composite prepared by continuous three-step electrodeposition. Mater Sci Eng: A 288(1): 26-33 (2000)

[209] Cha S I, Kim K T, Arshad S N, Mo C B, Hong S H. Extraordinary strengthening effect of carbon nanotubes in metal-matrix nanocomposites processed by molecularlevel mixing. Adv Mater 17(11): 1377-1381 (2005)

[210] Munir K, Wen C, Li Y. Graphene nanoplateletsreinforced magnesium metal matrix nanocomposites with superior mechanical and corrosion performance for biomedical applications. J Magnes Alloy 8(1): 269-290 (2020)

[211] Chu K, Wang F, Li Y B, Wang X H, Huang D J, Geng $\mathrm{Z}$ R. Interface and mechanical/thermal properties of graphene/copper composite with $\mathrm{Mo}_{2} \mathrm{C}$ nanoparticles grown on graphene. Compos Part A: Appl Sci Manuf 109: 267-279 (2018)

[212] Jia Z F, Li H Q, Zhao Y, Frazer L, Qian B S, Borguet E, Ren F, Dikin D A. Electrical and mechanical properties of poly(dopamine)-modified copper/reduced graphene oxide composites. J Mater Sci 52(19): 11620-11629 (2017)

[213] Zhao X Y, Tang J C, Yu F X, Ye N. Preparation of graphene nanoplatelets reinforcing copper matrix composites by electrochemical deposition. J Alloys Compd 766: 266-273 (2018)

[214] Arab M, Marashi S P H. Effect of graphene nanoplatelets (GNPs) content on improvement of mechanical and tribological properties of AZ31 Mg matrix nanocomposite. Tribol Int 132: 1-10 (2019)

[215] Khobragade N, Sikdar K, Kumar B, Bera S, Roy D. Mechanical and electrical properties of copper- graphene nanocomposite fabricated by high pressure torsion. $J$ Alloys Compd 776: 123-132 (2019)

[216] Chu K, Liu Y P, Wang J, Geng Z R, Li Y B. Oxygen plasma treatment for improving graphene distribution and mechanical properties of graphene/copper composites. Mater Sci Eng: A 735: 398-407 (2018)

[217] Zhao Y B, Peng X H, Fu T, Zhu X F, Hu N, Yan C. Strengthening mechanisms of graphene coated copper under nanoindentation. Comp Mater Sci 144: 42-49 (2018)

[218] Gao X, Yue H Y, Guo E J, Zhang H, Lin X Y, Yao L H,
Wang B. Preparation and tensile properties of homogeneously dispersed graphene reinforced aluminum matrix composites. Mater Design 94: 54-60 (2016)

[219] Fu K, Zhang X, Shi C S, Liu E Z, He F, Li J J, Zhao N Q, He C N. An approach for fabricating Ni@graphene reinforced nickel matrix composites with enhanced mechanical properties. Mater Sci Eng: A 715: 108-116 (2018)

[220] Gao X, Yue H Y, Guo E J, Zhang S L, Yao L H, Lin X Y, Wang B, Guan E H. Tribological properties of copper matrix composites reinforced with homogeneously dispersed graphene nanosheets. J Mater Sci Technol 34(10): 1925-1931 (2018)

[221] Zhang S, Ma T B, Erdemir A, Li Q Y. Tribology of two-dimensional materials: From mechanisms to modulating strategies. Mater Today 26: 67-86 (2019)

[222] Mai Y J, Li Y G, Li S L, Zhang L Y, Liu C S, Jie X H. Self-lubricating $\mathrm{Ti}_{3} \mathrm{C}_{2}$ nanosheets/copper composite coatings. J Alloys Compd 770: 1-5 (2019)

[223] Wang S Y, Han S B, Xin G Q, Lin J L, Wei R H, Lian J, Sun K, Zu X T, Yu Q K. High-quality graphene directly grown on $\mathrm{Cu}$ nanoparticles for $\mathrm{Cu}$-graphene nanocomposites. Mater Design 139: 181-187 (2018)

[224] Mai Y J, Chen F X, Lian W Q, Zhang L Y, Liu C S, Jie $\mathrm{X}$ H. Preparation and tribological behavior of copper matrix composites reinforced with nickel nanoparticles anchored graphene nanosheets. J Alloys Compd 756: 1-7 (2018)

[225] Lei Y, Jiang J L, Bi T T, Du J F, Pang X J. Tribological behavior of in situ fabricated graphene-nickel matrix composites. RSC Adv 8(39): 22113-22121 (2018)

[226] Wozniak J, Kostecki M, Cygan T, Buczek M, Olszyna A. Self-lubricating aluminium matrix composites reinforced with 2D crystals. Compos Part B: Eng 111: 1-9 (2017)

[227] Loganathan A, Rengifo S, Hernandez A F, Emirov Y, Zhang C, Boesl B, Karthikeyan J, Agarwal A. Effect of $2 \mathrm{D} \mathrm{WS}_{2}$ addition on cold-sprayed aluminum coating. $J$ Therm Spray Technol 26(7): 1585-1597 (2017)

[228] Zhai W Z, Shi X L, Yao J, Ibrahim A M M, Xu Z S, Zhu Q S, Xiao Y C, Chen L, Zhang Q X. Investigation of mechanical and tribological behaviors of multilayer graphene reinforced $\mathrm{Ni}_{3} \mathrm{Al}$ matrix composites. Compos Part B: Eng 70: 149-155 (2015)

[229] Zhai W Z, Srikanth N, Kong L B, Zhou K. Carbon nanomaterials in tribology. Carbon 119: 150-171 (2017)

[230] Wang J F, Jin X X, Li C H, Wang W J, Wu H, Guo S Y. Graphene and graphene derivatives toughening polymers: Toward high toughness and strength. Chem Eng J 370: 831-854 (2019)

[231] Hussein A, Kim B. Graphene/polymer nanocomposites: 
The active role of the matrix in stiffening mechanics. Compos Struct 202: 170-181 (2018)

[232] Huang T, Xin Y S, Li T S, Nutt S, Su C, Chen H M, Liu P, Lai Z L. Modified graphene/polyimide nanocomposites: Reinforcing and tribological effects. ACS Appl Mater Interfaces 5(11): 4878-4891 (2013)

[233] Li Y L, Wang S J, Wang Q, Xing M. A comparison study on mechanical properties of polymer composites reinforced by carbon nanotubes and graphene sheet. Compos Part B: Eng 133: 35-41 (2018)

[234] Hu J T, Huang Y, Zeng X L, Li Q, Ren L L, Sun R, Xu J B, Wong C P. Polymer composite with enhanced thermal conductivity and mechanical strength through orientation manipulating of BN. Compos Sci Technol 160: 127-137 (2018)

[235] Fei M M, Lin R Z, Deng Y M, Xian H X, Bian R J, Zhang $\mathrm{X}$ L, Cheng $\mathrm{J}$ G, Xu C X, Cai D Y. Polybenzimidazole/Mxene composite membranes for intermediate temperature polymer electrolyte membrane fuel cells. Nanotechnology 29(3): 035403 (2018)

[236] Khan M B, Jan R, Habib A, Khan A N. Evaluating mechanical properties of few layers $\mathrm{MoS}_{2}$ nanosheetspolymer composites. Adv Mater Sci Eng 2017: 3176808 (2017)

[237] Liu M F, Papageorgiou D G, Li S H, Lin K L, Kinloch I A, Young R J. Micromechanics of reinforcement of a graphene-based thermoplastic elastomer nanocomposite. Compos Part A: Appl Sci Manuf 110: 84-92 (2018)

[238] Fang H M, Bai S L, Wong C P. Thermal, mechanical and dielectric properties of flexible $\mathrm{BN}$ foam and $\mathrm{BN}$ nanosheets reinforced polymer composites for electronic packaging application. Compos Part A: Appl Sci Manuf 100: 71-80 (2017)

[239] Luo H B, Sui Y W, Qi J Q, Meng Q K, Wei F X, He Y Z. Mechanical enhancement of copper matrix composites with homogeneously dispersed graphene modified by silver nanoparticles. J Alloys Compd 729: 293-302 (2017)

[240] Khan U, May P, O’Neill A, Coleman J N. Development of stiff, strong, yet tough composites by the addition of solvent exfoliated graphene to polyurethane. Carbon 48(14): 4035-4041 (2010)

[241] O’Neill A, Khan U, Coleman J N. Preparation of high concentration dispersions of exfoliated $\mathrm{MoS}_{2}$ with increased flake size. Chem Mater 24(12): 2414-2421 (2012)

[242] Ren X Y, Yang X, Xie G X, Luo J B. Black Phosphorus Quantum Dots in Aqueous Ethylene Glycol for Macroscale Superlubricity. ACS Appl Nano Mater, in Press, DOI 10.1021/acsanm.0c00841.

[243] King J A, Klimek D R, Miskioglu I, Odegard G M. Mechanical properties of graphene nanoplatelet/epoxy composites. J Compos Mater 49(6): 659-668 (2015)

[244] Polschikov S V, Nedorezova P M, Klyamkina A N, Kovalchuk A A, Aladyshev A M, Shchegolikhin A N, Shchegolikhin V G, Muradyan V E. Composite materials of graphene nanoplatelets and polypropylene, prepared by in situ polymerization. J Appl Polym Sci 127(2): 904-911 (2013)

[245] Costa P, Nunes-Pereira J, Oliveira J, Silva J, Moreira J A, Carabineiro S A C, Buijnsters J G, LancerosMendez S. High-performance graphene-based carbon nanofiller/polymer composites for piezoresistive sensor applications. Compos Sci Technol 153: 241-252 (2017)

[246] Ren P G, Di Y Y, Zhang Q, Li L, Pang H, Li Z M. Composites of ultrahigh-molecular-weight polyethylene with graphene sheets and/or MWCNTs with segregated network structure: Preparation and properties. Macromol Mater Eng 297(5): 437-443 (2012)

[247] Yang Y C, Rigdon W, Huang X Y, Li X D. Enhancing graphene reinforcing potential in composites by hydrogen passivation induced dispersion. Sci Rep 3(1): 2086 (2013)

[248] Jiang R R, Zhou X F, Fang Q L, Liu Z P. Coppergraphene bulk composites with homogeneous graphene dispersion and enhanced mechanical properties. Mater Sci Eng: A 654: 124-130 (2016)

[249] Ponraj N V, Vettivel S C, Azhagurajan A, Sahaya Shajan X, Nabhiraj P Y, Theivasanthi T, Selvakumar P, Lenin A H. Effect of milling on dispersion of graphene nanosheet reinforcement in different morphology copper powder matrix. Surf Interfaces 9: 260-265 (2017)

[250] Saboori A, Moheimani S K, Dadkhah M, Pavese M, Badini C, Fino P. An overview of key challenges in the fabrication of metal matrix nanocomposites reinforced by graphene nanoplatelets. Metals 8(3): 172 (2018)

[251] Li Z L, Young R J, Wilson N R, Kinloch I A, Vallés C, $\mathrm{Li} Z$. Effect of the orientation of graphene-based nanoplatelets upon the Young's modulus of nanocomposites. Compos Sci Technol 123: 125-133 (2016)

[252] Huang T, Lu R G, Su C, Wang H N, Guo Z, Liu P, Huang Z Y, Chen H M, Li T S. Chemically modified graphene/polyimide composite films based on utilization of covalent bonding and oriented distribution. ACS Appl Mater Interfaces 4(5): 2699-2708 (2012)

[253] Chu K, Wang F, Wang X H, Huang D J. Anisotropic mechanical properties of graphene/copper composites with aligned graphene. Mater Sci Eng: A 713: 269-277 (2018)

[254] Jan R, May P, Bell A P, Habib A, Khan U, Coleman J N. Enhancing the mechanical properties of $B N$ nanosheet- polymer composites by uniaxial drawing. Nanoscale 6(9): 4889-4895 (2014)

[255] Wang F, Wang H Y, Mao J. Aligned-graphene 
composites: A review. J Mater Sci 54(1): 36-61 (2019)

[256] Wu J R, Huang G S, Li H, Wu S D, Liu Y F, Zheng J. Enhanced mechanical and gas barrier properties of rubber nanocomposites with surface functionalized graphene oxide at low content. Polymer 54(7): 19301937 (2013)

[257] Zhang Y L, Wang Y, Yu J R, Chen L, Zhu J, Hu Z M. Tuning the interface of graphene platelets/epoxy composites by the covalent grafting of polybenzimidazole. Polymer 55(19): 4990-5000 (2014)

[258] Chhetri S, Adak N C, Samanta P, Mallisetty P K, Murmu N C, Kuila T. Interface engineering for the improvement of mechanical and thermal properties of covalent functionalized graphene/epoxy composites. $J$ Appl Polym Sci 135(15): 46124 (2018)

[259] Chen H, Guo D, Xie G X, Pan G S. Mechanical model of nanoparticles for material removal in chemical mechanical polishing process. Friction 4(2): 153-164 (2016)

[260] Buehler M J, Misra A. Mechanical behavior of nanocomposites. MRS Bull 44(1): 19-24 (2019)

[261] Lu Z Y, Hanif A, Sun G X, Liang R, Parthasarathy P, Li Z J. Highly dispersed graphene oxide electrodeposited carbon fiber reinforced cement-based materials with enhanced mechanical properties. Cem Concr Compos 87: 220-228 (2018)

[262] Chen L, Chai S G, Liu K, Ning N Y, Gao J, Liu Q F, Chen F, Fu Q. Enhanced epoxy/silica composites mechanical properties by introducing graphene oxide to the interface. ACS Appl Mater Interfaces 4(8): 4398- 4404 (2012)

[263] Lewandowski J J, Seifi M. Metal additive manufacturing: A review of mechanical properties. Annu Rev Mater Res 46(1): 151-186 (2016)

[264] Naguib M, Mochalin V N, Barsoum M W, Gogotsi Y. 25th anniversary article: MXenes: A new family of two-dimensional materials. Adv Mater 26(7): 9921005 (2014)

[265] Das S, Pandey D, Thomas J, Roy T. The role of graphene and other 2D materials in solar photovoltaics. Adv Mater 31(1): 1802722 (2018)

[266] Wang Z Y, Mi B X. Environmental applications of 2D molybdenum disulfide $\left(\mathrm{MoS}_{2}\right)$ nanosheets. Environ. Sci. Technol. 51(15): 8229-8244 (2017)

[267] Campbell M G, Sheberla D, Liu S F, Swager T M, Dinc ă M. $\mathrm{Cu}_{3}$ (hexaiminotriphenylene) ${ }_{2}$ : An electrically conductive 2D metal-organic framework for chemiresistive sensing. Angew Chem Int Ed Engl 54(14): 4349-4352 (2015)

[268] Yu X W, Cheng H H, Zhang M, Zhao Y, Qu L T, Shi G Q. Graphene-based smart materials. Nat Rev Mater 2(9): 17046 (2017)
[269] Hazarika A, Deka B K, Kim D Y, Jeong H E, Park Y B, Park H W. Woven kevlar fiber/polydimethylsiloxane/ reduced graphene oxide composite-based personal thermal management with freestanding $\mathrm{Cu}-\mathrm{Ni}$ core-shell nanowires. Nano Lett 18(11): 6731-6739 (2018)

[270] Vlassiouk I, Polizos G, Cooper R, Ivanov I, Keum J K, Paulauskas F, Datskos P, Smirnov S. Strong and electrically conductive graphene-based composite fibers and laminates. ACS Appl Mater Interfaces 7(20): 10702-10709 (2015)

[271] Trache D, Hussin M H, Hui Chuin C T, Sabar S, Fazita M R N, Taiwo O F A, Hassan T M, Haafiz M K M. Microcrystalline cellulose: Isolation, characterization and bio-composites application-A review. Int J Biol Macromol 93: 789-804 (2016)

[272] Dong Y F, Wu Z S, Ren W C, Cheng H M, Bao X H. Graphene: A promising 2D material for electrochemical energy storage. Sci Bull 62(10): 724-740 (2017)

[273] Cha C, Shin S R, Annabi N, Dokmeci M R, Khademhosseini A. Carbon-based nanomaterials: Multifunctional materials for biomedical engineering. ACS Nano 7(4): 2891-2897 (2013)

[274] Goenka S, Sant V, Sant S. Graphene-based nanomaterials for drug delivery and tissue engineering. $J$ Control Release 173: 75-88 (2014)

[275] Dai C, Lin H, Xu G, Liu Z, Wu R, Chen Y. Biocompatible 2D titanium carbide (MXenes) composite nanosheets for $\mathrm{pH}$-Responsive MRI-guided tumor hyperthermia. Chem Mater 29(20): 8637-8652 (2017)

[276] Zhang X L, Xu Y, Zhang X, Wu H, Shen J B, Chen R, Xiong Y, Li J, Guo S Y. Progress on the layer-by-layer assembly of multilayered polymer composites: Strategy, structural control and applications. Prog Polym Sci 89: 76-107 (2019)

[277] Yu X Q, Zhang W S, Zhang P P, Su Z Q. Fabrication technologies and sensing applications of graphenebased composite films: Advances and challenges. Biosens Bioelectron 89: 72-84 (2017)

[278] Yang J, Bao W Z, Jaumaux P, Zhang S T, Wang C Y, Wang G X. MXene-based composites: Synthesis and applications in rechargeable batteries and supercapacitors. Adv Mater Interfaces 6(8): 1802004 (2019)

[279] Wu Z S, Liu Z Y, Parvez K, Feng X L, Müllen K. Ultrathin printable graphene supercapacitors with AC line-filtering performance. Adv Mater 27(24): 36693675 (2015)

[280] Ling Z, Ren C E, Zhao M Q, Yang J, Giammarco J M, Qiu J S, Barsoum M W, Gogotsi Y. Flexible and conductive MXene films and nanocomposites with high capacitance. Proc Natl Acad Sci USA 111(47): 16676-16681 (2014) 
[281] Liu P W, Cottrill A L, Kozawa D, Koman V B, Parviz D, Liu A T, Yang J F, Tran T Q, Wong M H, Wang S, et al. Emerging trends in $2 \mathrm{D}$ nanotechnology that are redefining our understanding of "Nanocomposites".

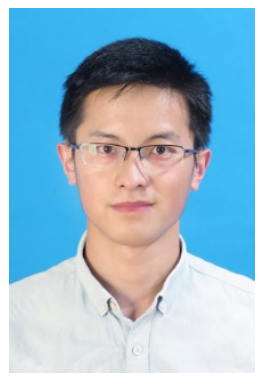

Zhengjia JI. He received his Ph.D. degree in materials science and engineering from China University of Geosciences (Wuhan) in 2017. Afterward, he worked as a postdoctoral research fellow working with Prof. Jianbin LUO and Prof. Guoxin XIE at State Key Laboratory

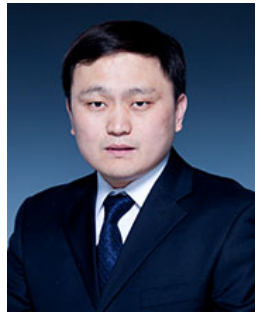

Guoxin XIE. He received his Ph.D. degree at Tsinghua University, China, in 2010, majoring in mechanical engineering. After that, he spent two years at State Key Laboratory of Tribology, Tsinghua University, China, for postdoctoral research. From 2012 to 2014, he worked at Royal Institute of Technology, Sweden, for another two-year post-

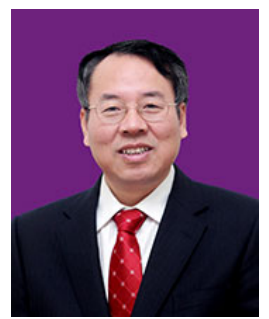

Jianbin LUO. He received his B.Eng. degree from Northeastern University in 1982, and got his M.Eng. degree from Xi'an University of Architecture and Technology in 1988. In 1994, he received his Ph.D. degree from Tsinghua University and then joined the faculty of Tsinghua University. Prof. Jianbin LUO is an academician of the Chinese Academy of Sciences and a Yangtze River Scholar Distinguished
Nano Today 21: 18-40 (2018)

[282] Wang W, Xie G X, Luo J B. Superlubricity of black phosphorus as lubricant additive. ACS Appl Mater Inter 10(49): 43203-43210 (2018)

of Tribology, Tsinghua University, Beijing, China. He is currently a lecturer at Qinghai University, China. He has published more than 10 papers in international journals. His major research areas include friction materials, self-lubrication materials, and 2D materials.

doctoral research. Since 2014, he has worked at Tsinghua University as an associate professor. His research interests include intelligent self-lubrication, electric contact lubrication, etc. He has published more than 50 referred papers in the international journals. He won several important academic awards, such as Chinese Thousands of Young Talents, the Excellent Doctoral Dissertation Award of China, and Ragnar Holm Plaque from KTH, Sweden.

Professor of Tsinghua University, Beijing, China. He was awarded the STLE International Award (2013), the Chinese National Technology Progress Prize (2008), the Chinese National Natural Science Prize (2018, 2001), and the Chinese National Invention Prize (1996). Prof. LUO has been engaged in the research of thin film lubrication and tribology in nanomanufacturing. He has been invited as a keynote or plenary speaker for 20 times on the international conferences. 